\title{
The Use of a Scoring Rubric in an Online Research Methodology Course
}

\author{
Kayla Bartlett*, Jacqui Floyd*, Shanda Davis*, Greg Haas*, Kathy Cox*, \\ Anthony J. Onwuegbuzie** \& Rebecca K. Frels ${ }^{1 *}$ \\ *Department of Educational Leadership and Counseling, Sam Houston State University \\ Box 2119, Huntsville, Texas 77341-2119, USA \\ E-mail: tonyonwuegbuzie@aol.com \\ ${ }^{1}$ *Lamar University, Beaumont, Texas, USA
}

Received: November 19, 2011 Accepted: January 16, 2012 Published: April 4, 2012 doi:10.5296/ije.v4i2.1604 URL: http://dx.doi.org/10.5296/ije.v4i2.1604

\begin{abstract}
Research methodology courses can be the most difficult courses in master's-level programs representing the social, behavioral, and health sciences because, in these courses, students typically are expected to learn to think critically and contextually about social and/or academic problems in addition to learning new terminology and methodological concepts not previously part of each specific discipline. Further, the challenges of online learning might increase due to the nature of research methodology courses and the new concepts taught. Thus, as students and instructors of an online research methodology course, we describe the use of a scoring rubric as a performance assessment and provide our student research proposal project as an exemplar of effectively developing research knowledge, skills, and dispositions for use in future online learning of research methodologies.
\end{abstract}

Keywords: research course, performance assessment, online, research methods, rubric 
Research methodology courses often represent required courses in graduate-level programs - particularly, master's-level programs - among virtually all disciplines in the social, behavioral, and health science fields and beyond. In these courses, graduate students typically are expected to learn to think critically and contextually about ways that research impacts social problems (Vandiver \& Walsh, 2010). As noted by Onwuegbuzie, Slate, Paterson, Watson, and Schwartz (2000):

Their experiences in these courses might "cement their attitudes towards the field of research, and thus determine whether they become consumers of research in the future (Onwuegbuzie, DaRos, \& Ryan, 1997; Ravid \& Leon, 1995). However, although the goal of many educational research instructors is to produce students with research consumer skills (i.e., the ability to read, to interpret, to synthesize, and to utilize research) and research production skills (i.e., the ability to design and to implement original research studies) (Ravid \& Leon, 1995), many students who have completed research methodology courses report being inadequately prepared either to understand or to conduct research (Fleming, 1988; Green \& Kvidahl, 1990; Rackliffe, 1988). Moreover, many students typically experience lower levels of performance in these courses than in their other graduate-level classes. These students often view educational research courses as merely a hurdle, which they must overcome in order to obtain their degrees... (p. 53)

Further, many students experience a unique anxiety in such courses (Kracker, 2002; Murtonen, 2005; Onwuegbuzie, 1997a, 1997b; Papanastasiou \& Zembylas, 2008).

According to the Sloan-C (2009) national survey of online learning, the number of students taking online courses in higher education has grown at a higher rate than has the number receiving face-to-face instruction, with approximately $30 \%$ of the total higher education student population enrolled in at least one online course. The combination of teaching a research methodology course and teaching online, thus, can be problematic. In fact, pedagogical strategies differ tremendously between research methodology courses taught online and research methodology courses taught face-to-face. Indeed, as surmised by Ivankova and Stick (2007), online courses create the need for instructors of research methodology courses to change their pedagogical roles from being teachers to serving as facilitators of cognitive development, learning, educational growth, and achievement. Yet, regardless of the instructional format, two components are critical in order for students to be successful in research methodology courses: autonomy and self-directed learning (Girod \& Wofcikiewicz, 2009; Onwuegbuzie, Frels, Leech, \& Collins, 2011). As such, the purpose of this article is to provide support for instructors of online research courses through the use of a scoring rubric both to guide and to assess the comprehensive project that is assigned in many research methodology courses - the research proposal. Specifically, as students who wrote the research proposal and instructors who taught the course, we collaboratively introduce the components of the Scoring Rubric (Onwuegbuzie, 2011) and provide our exemplar of the final product written in a master's-level research methodology course.

\section{Conceptual Framework}

Hutchinson (1995) explained that performance assessments can utilize flexible time 
frames, open-ended formats, and cooperative and collaborative learning techniques. Further, as noted by Elliot (1995), students' levels of performance can be improved when the performance assessment comprises the following components: (a) selecting assessment tasks that are aligned clearly and are connected to the material being taught; (b) specifying clearly the scoring criteria for the assessment task to students prior to attempting the task; (c) providing students with explicit statements of standards and/or various models of acceptable performance before they attempt a task; (d) encouraging students to undertake self-assessments of their performances; and (e) interpreting students' performances by comparing them to those of other students, as well as to standards that are developmentally appropriate. Therefore, the use of a rubric within the framework of performance assessment for teaching and learning research methods promotes active learning, which, in turn, and as explained by Cobb (1993), increases students' sense of responsibility. The remainder of this article is presented using the five components of performance assessment (Elliot, 1995) as they pertained to our course: (a) Assessment Tasks: The Research Proposal; (b) The Criteria: The Scoring Rubric; (c) Standards for Performance: Instructor Feedback; and (d) Self-Assessments: An Exemplar of the Research Proposal; (e) Interpreting Performance: A Conclusion of the Process. The student exemplar of the final product is presented in Appendix A and the Scoring Rubric: Part I and Part II is presented in Appendix B. Finally, in Appendix C, we present an example of instructor feedback using the Scoring Rubric Part I and Part II.

\section{Assessment Tasks: The Research Proposal}

In a recent study by Frels, Onwuegbuzie, Leech, and Collins (2011), whereby they interviewed 12 leading methodologists who also taught research methodology courses, the primary project of a research proposal was assigned most often as a final project. As noted by Fink (2003), a final project is important for the application of skills in student learning. Thus, as instructors of the research course, we incorporated the research proposal as a type of performance assessment, which as an assignment that is clearly aligned with course objectives and, as noted by Elliot (1995), connects students intimately to the material being taught.

After moving through the phases of foundational learning of research philosophy, research traditions (e.g., quantitative, qualitative, mixed methods), research sampling, research design, and various research data collection methods and various mediating assignments (e.g., conducting a survey, interpreting basic statistics), student groups are instructed to select a topic and to create the research prospectus. The research prospectus is the first draft of the research proposal, whereby students are required to provide sufficient information about the statement of the problem, list of potential topics and/or headings for the literature review section, theoretical framework/conceptual framework, rationale of the study, statement of the purpose, research questions, hypotheses (if relevant), educational significance, population/context, sampling frame, selection criterion, participants, instruments, procedures, and analyses. After receiving feedback on the prospectus assignment, student groups embark on the final assignment of the research proposal. The syllabus of the course presents this assignment as follows: 
$\underline{\text { Research Proposal (150 points/300 points) }}$

Each cooperative learning group will submit a written research proposal. Each research proposal is worth 150 points. The goal is to allow students to practice formulating research questions, conducting reviews of the literature, selecting the research design and sampling design, identifying and/or designing the instrument(s), developing the procedures, selecting appropriate analyses, and identifying potential limitations of the study. That is, the research proposal should contain all the major elements of a traditional research proposal. Simply put, the goal is to allow students the opportunity cooperatively to practice the decision-making skills required for planning a research study with feedback from the instructor. To this end, the research proposal must be original in its entirety. It is expected that, upon completion of the proposal, students will be very familiar with the research process. As such, the research proposal will play a major role in demystifying the research process. The main body (i.e., not including reference pages and appendices) must not exceed 20 pages using 12-point font, 1-inch margins all around, and double spaces throughout. That is, the reference list page should not begin any later than on page 21. Manuscripts in which this 20-page limit is exceeded will not be graded and will be assigned a score of zero. Please note that one point will be deducted for every missing, incomplete, or inconsistent reference. Detailed feedback will be given, utilizing a scoring rubric. For each individual, his/her group score will be weighted by the participation score, such that if he/she receives $100 \%$ of the participation points available, his/her individual score will be exactly equivalent to the group score. If the student receives $90 \%$ of the participation points available, his/her individual score will be worth $90 \%$ of the group score, and so on. This research proposal should be completely written in APA style (sixth edition). Thus, you should check, if you are not certain, to verify all the parts that must be included in a research proposal. Your submission must include all of these parts. Missing parts and APA errors will result in substantial reductions in the grade you receive.

\section{The Criteria: The Scoring Rubric}

Before beginning the research proposal, each group decides on the research tradition: quantitative, qualitative, or mixed methods. For this assignment, according to which approach is selected, students are given a checklist that is specific to the components needed for the selected approach. For the purpose of this article and because we as students selected to design a mixed methods research study, we will discuss this checklist, hereafter referred to as the Scoring Rubric, which was specific to mixed methods research. The utility of discussing this rubric is that virtually all of the items that appear in both the Scoring Rubric specific to quantitative research and the Scoring Rubric specific to qualitative research appear in the Scoring Rubric specific to mixed methods research. The Scoring Rubric comprises two sections: (a) content (Part I), the rubric for instructors for feedback pertaining to the essential components of mixed research; and (b) style (Part II), the rubric for feedback pertaining to adherence to American Psychological Association (APA, 2010) guidelines.

Part I of the Scoring Rubric pertains to 10 essential sections of a research report: (a) title, (b) method, (c) instruments, (d) procedure, (e) analysis, (f) legitimation, (g) results, (h) 
discussion, (i) reference list, and (j) appendix. Appendix A presents the Rubric Part I and the items included in the 10 essential sections. It should be noted that as instructors of the course, we continually revise and update the Scoring Rubric with new concepts, theories, procedures, and language as they emerge.

Part II of the Scoring Rubric considers the writing proficiency of student groups in the presentation of concepts. Further, Part II of the Rubric is presented in the same organizational format as Part I. Similar to Part I, it allows the instructor to provide additional points for a student who has provided detailed references. Thus, Part II of the Checklist facilitates the technical application of writing style important for students to succeed as self-directed learners. Appendix A also presents Part II of the Rubric (i.e., adherence to APA [2010] style guidelines), directly after Part I of the Rubric.

\section{Standards for Performance: Instructor Feedback}

As described by Frels, Sharma, Onwuegbuzie, Leech, and Stark (2010), the act of providing detailed feedback on the part of instructors is central for instilling a sense of direction and autonomy for student learning. It is the feedback of the research proposal that instills confidence and allows students to reflect on their levels of performance for greater responsibility in future actions (Butler, 2004). As instructors of the research methodology course, we utilize the Review tab of Microsoft Word-specifically the comment and tracking function - to provide details for students pertaining to both Part I and Part II of the Scoring Rubric. Appendix B presents some examples of feedback on the exemplar assignment presented in this article.

In addition, even though students progress to other courses in a master's program, by attending and affirming the feedback, students increase awareness of research components and increase writing skills important for success in future courses and careers. Kolb (1984) described this process as a reflective and meaning-making endeavor and specified that attending (spending time with the event) and affirming (accepting and valuing the feedback, even if the first response might be to disregard it) represented positive and developmental components of learning.

\section{Self-Assessments: An Exemplar of the Research Proposal}

Elliot (1995) explained that the performance assessment includes the means for students to undertake self-assessments of their levels of performance. Uniquely, the Scoring Rubric is the guide for constructing the research proposal and by working in groups, students begin the phase of self-assessing not only this major project, but also the overall learning of content to be applied in the project. As students, we selected the topic of school culture in exemplary Title 1 schools (i.e., U. S. federal programs that provide money to schools with high numbers or high percentages of students from low-socioeconomic backgrounds) and, as noted previously, we used a mixed methods research approach and the aforementioned specific rubric to guide our writing. After feedback, and through a type of self-assessment of our final product, we hope that our exemplar can serve as a model for future instructors and students alike to address the component in performance identified by Elliot (1995) for a standard 
and/or model of acceptable performance. The completed research proposal assignment is presented in Appendix A.

\section{Interpreting Performance: A Conclusion of the Process}

Our exemplar of the research proposal presented in Appendix A presents the many details important to the research process and important to include when writing a research proposal. As noted by Elliot (1995), it is important to assess and to interpret performance with respect to other students, as well as with regard to standards that are appropriate. Therefore, the use of the Scoring Rubric as our guide through the mode of group work, specifically-evaluating each other's contribution to the group project-facilitated interpretation of both the process and performance. The social processes that are connected to the acquisition of knowledge (Piaget, 1954; Vygotsky, 1978) were a component of the performance assessment and the use of the Scoring Rubric to stimulate our thought processes, questions to each other, and conversations. The interaction of writing and feedback (socially and contextually) among students and between instructors and students after using the Scoring Rubric is vital to the process for interpreting the level of performance in the research methodology course. In closing, and as a final testimony to this interaction, we present our collaborative outcomes of experiences in our online research methodology course. The independent skills required to succeed not only with online learning specifically but also with the online learning of research methodology, can be facilitated through the explicit guidelines contained in instruments such as the Scoring Rubric, which might provide a type of launching pad for self-directed learning. Further, we hope that by providing both the Scoring Rubric and an example of our research proposal, we can contribute to the future strategies used by online research methodology instructors to include performance assessment and an effective scoring rubric to guide student learning.

\section{References}

American Psychological Association. (2010). Publication manual of the American Psychological Association (6th ed.). Washington, DC: Author.

Butler, S. (2004). Question: When is a comment not worth the paper it's written on? Answer: When it is accompanied by a level, grade or mark! Teaching History, 115, 37-41.

Cobb, G. (1993) Reconsidering statistics education: A National Science Foundation Conference. Journal of Statistics Education, 1(1). Retrieved by e-mail at: archive@jse.stat.ncsu.edu.

Elliott, S. N. (1995) Creating meaningful performance assessments. ERIC Digest E531 (ERIC Document Reproduction Service No. ED381985).

Fink, L. D. (2003). Creating significant learning experiences in college classrooms. San Francisco, CA: Jossey-Bass.

Frels, R. K., Onwuegbuzie, A. J., Leech, N. L., \& Collins, K. M. T. (2012). Pedagogical 
strategies used by selected leading mixed methodologists in mixed research courses. Manuscript submitted for publication.

Frels, R. K., Sharma, B., Onwuegbuzie, A. J., Leach, N. L., \& Stark, M. (2011). The Use of a Checklist and Qualitative Notebooks for an Interactive Process Teaching and Learning Qualitative Research. The Journal of Effective Teaching, 11(1), 60-77.

Girod, M., \& Wofcikiewicz, S. (2009). Comparing distance vs. campus-based delivery of research methods courses. Educational Research Quarterly 33(2), 47-61.

Hutchinson, N. L. (1995). Performance assessments of career development. ERIC Digest (ERIC Document Reproduction Service No. ED414518).

Ivankova, N., \& Stick, S. (2007). Online higher education programs: New challenges, new

frontiers, new learning, and new scholarship. In D. Wright, \& M. Miller (Eds.), Training higher education policy makers and leaders: A graduate program perspective (pp. 77-97). Charlotte, NC: Information Age Publishing/Greenwood Press.

Kolb, D. A. (1984). Experiential learning: Experience as the source of learning and development. Englewood Cliffs, NJ: Prentice Hall.

Kracker, J. (2002). Research anxiety and students' perceptions of research: An experiment, Part I: Effect of teaching Kuhlthau's ISP model. Journal of American Society of Science Technology, 53, 282-294. http://dx.doi.org/10.1002/asi.10040

Murtonen, M. (2005). University students' research orientations: Do negative attitudes exist toward quantitative methods? Scandinavian Journal of Educational Research 49: 263-80. http://dx.doi.org/10.1080/00313830500109568

Onwuegbuzie, A. J. (1997a). The teacher as researcher: The relationship between research anxiety and learning style in a research methodology course, College Student Journal, 31, 496-506. http://dx.doi.org/10.2466/pr0.1997.80.2.496

Onwuegbuzie, A. J. (1997b). Writing a research proposal: The role of library anxiety, statistics anxiety, and composition anxiety. Library and Information Science Research, 19, 5-33. http://dx.doi.org/10.1016/S0740-8188(97)90003-7

Onwuegbuzie, A. J. (2011). The scoring rubric. Unpublished manuscript. Sam Houston State University, Huntsville, TX.

Onwuegbuzie, A. J., Frels, R. K., Leech, N. L., \& Collins, K. M. T. (2011). A mixed research study of pedagogical approaches and student learning in doctoral-level mixed research courses. International Journal of Multiple Research Approaches, 5, 169-202.

Onwuegbuzie, A. J., Slate, J., Paterson, F., Watson, M., \& Schwartz, R. (2000). Factors associated with achievement in educational research courses. Research in the Schools, $7(1), 53-65$.

Papanastasiou, E. C., \& Zembylas, M. (2008). Anxiety in undergraduate research methods 
courses: Its nature and implications. International Journal of Research \& Method in Education, 31, 155-167. http://dx.doi.org/10.1080/17437270802124616

Piaget, J. (1954). The construction of reality in the child. New York, NY: Basic Books.

Sloan-C (2009). Learning on demand: Online education in the United States. Retrieved from http://sloanconsortium.org/publications/survey/learning_on_demand_sr2010

Vandiver, D. M., \& Walsh, J. A. (2010). Assessing autonomous learning in research methods courses: Implementing the student-driven research project. Active Learning in Higher Education, 11(1), 31-42. http://dx.doi.org/10.1177/1469787409355877

Vygotsky, L. S. (1978). Mind in society: The development of higher psychological processes. Cambridge, MA: Harvard University Press.

\section{Appendix A}

An Exemplar of the Research Proposal:

School Culture in Exemplary Title I Schools

Kayla Bartlett, Jacqui Floyd, Shanda Davis, Greg Haas, and Kathy Cox

Sam Houston State University

Most people believe that all schools are the same from the outside looking in (Ayers, 1995). The problem with that frame of mind is that schools are schools, not airplane factories or dairy farms; schools look like schools, and schools are run as schools, but with a little closer look, schools are extraordinarily different. The closer you get, the more different schools look. Each school has a distinctive feel.

This feel is so persistent and potent that people experience it immediately when walking into a school. Being accustomed to this experience there is worry about a school that lacks a particular feel. Somehow it has not been inhabited. It does not have a history; and it does not have a personality. People are not yet experiencing its culture.

Once there is a feel to the school's culture, however, it leaves a strong impression on everyone. The combination of the structural design, the symbols, the artifacts, the look and behavior of the people, the conversations had, and the treatment received - all this and much more-creates a memorable impression.

One definition of school culture is the deep pattern of values, beliefs, and traditions that have been formed over the course of its history (Deal \& Peterson, 1990). A school culture is formed by its school community, which includes teachers, administrators, board members, business leaders, and the students themselves (Johnson \& Christensen, 2010). Every member of a school community is either part of the cultural mission of the school, an obstacle to that mission, or part of a subculture with a different mission (Daresh, 2007). Our group believes that a positive school culture, from leadership downwards, has a tremendous impact on the performance of Title I schools. In this research we hope to identify what parts of a positive culture impacts the schools the most, and how much leadership plays a part in developing that 
culture (Sergiovanni, 1984). For ideas to research, we considered our own experiences as teachers (Johnson \& Christensen, 2010).

\section{Review of the Related Literature}

School culture includes the norms, values, and cultural artifacts shared by members of a school, which affects the school's overall functioning (Engels, Hotton, Devos, Bouckenooghe, \& Aelterman, 2008). Lunenburg and Ornstein (2008) further explained culture to include the history of the organization; myths and stories that explain the organization; cultural norms; heroes of the organization; and traditions, rituals, and ceremonies of the organization. The information discovered about characteristics of effective schools, schools containing a positive culture, leadership in exemplary schools, and effects of positive school culture on student achievement will be shared.

Effective schools and schools with a positive culture. Effective schools involve strong leadership, a climate of expectation, an orderly atmosphere, and effective communication (Kelley, Thornton, \& Daugherty, 2005). Relationships, including student to student, teacher to student, teacher to family, administrator to staff, and school to community, are important in creating good school culture (Keiser \& Schulte, 2009). Healthy schools set high standards for academics and possess appropriate leadership and collegiality (Macneil, Prater, \& Busch, 2009). Furthermore, according to Macneil et al. (2009), these effective schools contain several factors, such as goal focus, communication, optimal power equalization, resource utilization, cohesiveness, morale, innovativeness, autonomy, adaptation, and problem solving adequacy. More qualities of healthy schools include teachers who: feel good about their students, have confidence in their students' abilities, and possess a trustworthy relationship between administration and staff (Henderson et al., 2005). High commitment and performance also appear to be characteristics of schools that contain a healthy school culture (Engels et al., 2008). Moreover, teacher collaboration is prevalent in a successful school (Johnson, Snyder, Anderson, \& Johnson, 1996). Schools that possess shared views of fairness, justice, respect, cooperation, and compassion contain a positive sense of community (Keiser \& Schulte, 2009). According to Bryan and Henry (2008), Title I elementary schools must utilize the strengths found in children, their families, and communities. School-family-community partnerships help in establishing strong environments that students need to be successful (Bryan \& Henry, 2008).

Leadership. The link between effective school cultures and leadership is supported by educational research findings (Macneil et al., 2009). In fact, there is a strong association between effective principals and school cultures that support learning (Engels et al., 2008). Southworth and Du Quesnay (2005) surmised that school leadership plays an important role in the growth of schools. Overall, school culture, and the relationships that shape it, is strongly guided by the principal (Macneil et al., 2009). A principal who builds a culture promoting and encouraging learning helps students be successful. Viewing their school's environment in a holistic way allows leaders better to shape the values, beliefs, and attitudes crucial to creating an ideal learning environment (Macneil et al., 2009). The principal should act as an entrepreneur, with a vision, who is able to inspire and to motivate their staff (Engels 
et al., 2008). According to Howley, Woodrum, Burgess, and Rhodes (2009), a school operates best when leaders plan, implement policies, and initiate practices responsive to the culture of the community surrounding the school. School leadership is most effective when it embraces cultural norms and values of the community. In productive schools, answers to learning problems take place when administrators facilitate problem solving and express instructional standards (Johnson et al., 1996).

Student learning. School culture has an effect on student learning (Engels et al., 2008). In particular, Henderson et al. (2005) concluded that effective leadership increases student achievement. Teacher affiliation, resource support, and academic emphasis also strongly correlate with student achievement. Schools that hold their students to high expectations and maintain orderly environments obtain higher student achievement on standardized tests (Henderson et al., 2005). In addition, a strong leader, the climate of the school, and the attitudes of faculty and staff can directly affect student achievement (Kelley et al., 2005). According to Kelley et al. (2005),

School climate might be one of the most important ingredients of a successful instructional program. Without a climate that creates a harmonious and well functioning school, a high degree of academic achievement is difficult, if not downright impossible, to obtain (p. 19).

\section{Conceptual/Theoretical Framework}

The framework for this research proposal will be designed with the intentions of being able to apply our conclusions to help in the future development of Title I schools. Lester (2005) states that "a research framework is a basic structure of the ideas (i.e., abstractions and relationship) that serve as the basis for a phenomenon that is being investigated" (p. 458). Theoretical framework is based on formal theory, whereas conceptual frameworks are based on a wide array of sources. With this in mind, we have developed strong ideas that have built our framework. The first is that attitudes by staff and administration in schools have a strong influence on children learning. Second, the implementation of Title I funding from the No Child Left Behind (NCLB) Act has had a positive influence on improving economically disadvantaged students education. Also, the Texas Assessment of Knowledge and Skills (TAKS) test scoring system is an adequate measurement of educational progress within Texas Public Schools. We believe that all these components work together to shape successful Title I exemplary elementary schools.

\section{Purpose of Study}

More information is needed on school effectiveness with different populations, settings, and sites-specifically, successful Title I campuses. Title I schools are very unique and encompass unique students with an abundance of different needs. Much more information is needed on how to help students and staff be successful at these types of schools. Although research has been conducted on characteristics of effective schools, there is a lack of research focusing on successful Title I schools specifically; and additional research is needed regarding these schools. We believe that this study will contribute to the knowledge base of what is known about effective Title I schools. Furthermore, we believe the findings will help 
generate new ideas for other schools to implement. Finally, we hope the findings of this research will have an impact on the school at which we teach and other similar schools. The purpose of this study will be to investigate the characteristics of the school culture in 10 exemplary-rated Title I elementary campuses.

\section{Research Question(s) (Grand Tour Questions/Sub-Questions)}

The following research questions will be addressed: What are the strategies that are being taken by teachers, administration, and staff within exemplary elementary schools to achieve and to maintain exemplary status? How has/does parental involvement impact the academic achievement of students in exemplary Title I elementary schools? What are the distinguishing components in the climate and culture of exemplary Title I elementary schools? What is the leadership style utilized to lead the campus to achieve exemplary status in Title I elementary schools?

\section{Significance of the Study}

The research will target teachers, administrators, and other stakeholders involved in the academic achievement of students. The researchers will identify the characteristics of exemplary Title I elementary schools and the attitudes and behaviors of its students, teachers, and staff. It is hoped that the results of this study will identify effective concepts that are currently in place, and also enable the teachers, administrators, and other stakeholders to develop new programs, strategies, interventions, and so forth that will yield positive outcomes.

\section{Method}

\section{Participants}

The participants in this study will include administrators, teachers, and paraprofessionals of socioeconomically disadvantaged (Title I) elementary campuses that have achieved and/or maintained exemplary status. The sample members will be selected using convenience sampling. According to Onwuegbuzie and Collins (2007), a convenience sample consists of individuals who are available and willing to participate in a study. Purposeful random sampling and triangulation will be utilized to enable the collection of credible data from the selected respondents and to develop an understanding of the attitudes and behaviors that contribute to the different school's exemplary status. Johnson and Christensen (2010) defined triangulation as involving looking for convergence of findings from various methods while studying the same phenomenon.

Population context/size/population characteristics/selection-eligibility characteristics. The 10 elementary schools we will study have to meet two major requirements. The elementary campuses must be considered Title I eligible and recognized as Exemplary each of the previous 3 years. Title I schools are campuses that receive federal funding because of a high percentage of low-income students. The Elementary and Secondary Education Act (ESEA) was enacted in 1965 by the Johnson Administration in an effort to give all children an equal environment to learn. This title's purpose is to ensure that every child has a fair and 
equal chance to obtain a quality education and be proficient on state achievement standards and academic assessments (U.S. Department of Education, n.d.b). This act is better known today as NCLB. Forty percent of the students in eligible schools are considered low-income. Examples of how the funds are used include providing additional funds for extra instruction in reading and mathematics, and special programs such as preschool, after-school, and summer school (U.S Department of Education, n.d.a). Funds also are allocated to help involve parents in the education of their children, and to provide teachers and school staff with substantial opportunities for quality professional development. Funds are used in an overall attempt to close the achievement gap between low-and high-performance children (U.S Department of Education, n.d.b).

The second requirement is that the school has reached exemplary status all of the previous 3 years, as determined by the Texas Education Agency (TEA). There are three standards by which a campus may be labeled: Exemplary, Recognized, and Academically Acceptable. All three of these labels are determined by TAKS tests scores. This test has five large areas that are measured: Reading, Writing, Social Studies, Mathematics, and Science. Also, this test is administered to students from third grade through 11th grade. Testing for different subjects are staggered in years. For example, writing is tested in Grades 4 and 7, whereas social studies is graded in Grades 8, 10, and 11. To determine a school's standards, the number of students who score high enough to pass the test is divided by the total number of students. For a school to be Exemplary, at least $90 \%$ of students must pass all subject areas. For a school to be included in our research, they must officially meet these TEA requirements (TEA, 2010).

Sample size. Twenty-five participants from each of the 10 exemplary Title I elementary schools in the study will be interviewed. Johnson and Christensen (2010) mentioned that an intramethod mixing approach allows for quantitative as well as qualitative data to be obtained through a single method. The sample size for the intramethod questionnaire will depend on how many individuals respond.

Sample characteristics. It will be valuable to administer questionnaires to teachers, administrators, counselors, and any other teaching assistants who are involved in the day-to-day educational process on the campus. Johnson and Christensen (2010) explained that researchers are not limited to face-to-face interviews, because telephone interviews are acceptable forms of data collection.

\section{Instruments}

All 25 faculty and staff members at 10 exemplary Title I schools will be interviewed. The interview will consist of six open-ended questions. The interview questions are as follows:

1. In your own words, what role does culture play in your Title I school?

2. Describe the atmosphere at your school.

3. How are parents involved in their child's education?

4. How does the administration interact with the faculty and staff? 
5. Which policies and procedures at your school help your students be successful?

6. What are the attitudes of faculty and staff at your school toward meeting an exemplary standard?

Probing question will include: Can you think of some examples? Could you tell me more about your thinking on that? Each participant will be interviewed only once, using a formal interview guide approach. According to Johnson and Christensen (2010), this approach to interviewing involves specific questions being asked in any order; and the interviewer has freedom to rearrange the wording of questions. The interviews will be semi-structured, allowing the researchers to talk conversationally with the participants. Members of the research team will be responsible for interviewing at each school. The site used to interview will be a convenient and comfortable location within the school, such as the school library. At each school, the research team will interview three administrators (the principal, one assistant principal, and one counselor), 15 classroom teachers, and seven paraprofessionals. The interviews will be scheduled during each interviewee's conference time and will last between 20 and 30 minutes. Furthermore, a member checking or participant feedback approach will be implemented. This method consists of the researchers discussing conclusions made from the interviews with the actual participants to achieve accuracy (Johnson \& Christensen, 2010). This method will take place through a follow-up interview with participants.

Rationale for selection of instrument. By interviewing participants, we will be able to obtain a better grasp of the school culture through the participants' own words. The interviews will allow us to view better the participants' attitudes, thoughts, and beliefs about their school. In addition to the qualitative interviews, the research team will implement an intramethod questionnaire. Johnson and Christensen (2010) mentioned that an intramethod mixing approach allows for quantitative as well as qualitative data to be obtained through a single method. It is cost efficient and will provide data in various formats. The purpose of the questionnaire will be to obtain quantitative and qualitative data via a single tool. It will contain questions about the culture of the school, concerning topics such as leadership, relationships, parent involvement, curriculum, instruction, and community involvement. The questionnaire will consist of items created by the researchers.

Format of items. The questionnaire will consist of eight Likert-format items and 10 open-ended questions about school culture. The Likert-format items will ask participants to indicate each response from 1 to 4, with 1 representing never occurs, 2 representing sometimes occurs, 3 representing frequently occurs, and 4 representing always occurs. The goal will be to determine the frequency of certain occurrences at the school. The 10 open-ended questions will involve questions concerning leadership, relationships, parent involvement, curriculum, instruction, and community involvement at the school. The eight Likert-format items are:

1. Teachers and staff tell stories of celebrations that support the school's values.

2. The administration treats faculty and staff as equals. 
3. The school supports and appreciates new ideas by members of the school.

4. The school staff is encouraged to make instructional decisions rather than waiting for administrators to tell them what to do.

5. Teachers and staff discuss instructional strategies.

6. Teacher planning time is used to plan as teams rather than individually.

7. Parents are involved in their child's school experience.

8. The community plays an active role in the school.

Examples of qualitative questions include:

1. Describe the interaction among faculty and staff outside of school

2. Describe any unwritten traditions present at your school.

3. What are some ways the community is involved at your school?

4. What are some ways parents are involved at your school?

Administration, scoring/tabulating, and interpretation. The questionnaire will be administered through the use of Survey Monkey, a data collection tool. The link to the questionnaire will be sent out to all faculty and staff at the school by email. The email will explain the purpose of the study; and the faculty and staff will be encouraged to participate in filling out the questionnaire. The responses for each of the Likert-format items will be tabulated. Each response will be assigned a point value. A ranking of never occurs will be assigned 1 point, sometimes occurs will be assigned 2 points, frequently occurs will be assigned 3 points, and always occurs will be assigned 4 points. For an eight Likert-item scale, scores will range from a low of 8 (i.e., $8 \times 1$ ) to a high of 32 (i.e., $8 \times 4$ ), with high scores representing positive attitudes and interactions at the school. These scores then can be used to compare frequencies of occurrences at the campus. The open-ended responses will be tabulated as well.

Score reliability reported by instrument developers. Test-retest reliability will be obtained by administering the questionnaire to a test group of participants. One month later, the same questionnaire will be administered to the same group of participants; and the responses will be compared (Trochim, 2006).

Score reliability that will be computed in present study. The research team will conduct a follow-up study among the school, administering the same questionnaire several months later, to view the results obtained. The results of the questionnaire will be compared to those of the original study. Internal consistency score reliability will be calculated by using Cronbach's alpha. Scores for Cronbach's alpha usually range between 0 and 1. The closer Cronbach's alpha is to 1, the greater the internal consistency of the items (Gilem \& Gilem, 2003).

Content- and criterion-related validity reported by instrument developers. A panel of experts on school culture will review the questionnaire and suggest items that can be 
improved. The panel will let the research team know if the items will provide a good way of discovering information about the culture of the schools. Results of the questionnaire will be compared with characteristics from the Correlates of Effective Schools research by Lawrence Lezotte (Lezotte, 1991). These correlates consist of a safe and orderly environment, a climate of high expectations, instructional leadership, a clear and focused mission, the opportunity to learn and student time on task, frequent monitoring of student progress, and home-school relations (Lezotte, 1991). This comparison will help assure criterion-related validity by relating the data gathered in this study to another school effectiveness measure that has already been demonstrated to be valid.

Construct-related validity reported by instrument developers. Multiple operationalism, which is the use of different measures of a construct, will be employed (Johnson \& Christensen, 2010). The construct will be measured using a variety of ways, such as with interviews, quantitative questions, and qualitative questions. According to Johnson and Christensen (2010), the probability of acquiring a more complete as well as accurate representation of the construct increases as more measures of the same construct are implemented.

Development and validation procedures for any new instrument. After discussing the data that we plan to collect, consulting previously conducted studies, and researching components of a school culture, the research team will develop the items on the questionnaire. Peer review, the sharing of thoughts and interpretations with one's peers, will be used. Participant feedback, whereby responses received are actually verified with the participants themselves, will be utilized as well (Johnson \& Christensen, 2010). The survey also will be given to a test group of participants beforehand, to check for the understanding of the items included and the layout of the questionnaire.

\section{Procedures}

Ethical nature of data collection. All participants will be informed of the purpose, nature, and instruments used in the study through an informed consent form. This form will allow the participant to agree to be a part of a study after being informed of its purpose, procedures, risks, benefits, and confidentiality (Johnson \& Christensen, 2010). Additionally, the participants will be assured that all information shared or observed through the research will remain anonymous and confidential. This proposal will be submitted to the Institutional Review Board (IRB) for approval of this study as well. Data collectors will be trained concerning what specific characteristics and qualities to look for while interviewing. Furthermore, they will be trained concerning probing question techniques and how to watch for non-verbal responses while interviewing participants.

Timeline for data collection. The intramethod questionnaire will be administered at the beginning of the study. The faculty will be given 1 week to respond to the survey at each school. After this, a reminder email will be sent out, encouraging those who have not completed the survey to do so. After 1 additional week, the survey will be closed. Concerning interviews, the research team will plan to conduct approximately five interviews a day at each school, over a time period of approximately 1 week. 
Research paradigm. Our research paradigm will include pragmatism, because a mixed research approach will be carried out (Johnson \& Onwuegbuzie, 2004). Johnson and Christensen (2010) mentioned that a mixed research approach consists of both quantitative and qualitative components. Pragmatism involves the view of what works in practice and encourages social justice. Pragmatists believe in implementing the research design that will best allow the researchers to answer their research questions (Johnson \& Christensen, 2010). Our qualitative-dominant research design will allow us better to gather the thoughts and happenings at 10 Title I exemplary schools.

Research design. The research design will consist of a qualitative-dominant concurrent method. This method includes the qualitative approach being given more weight than the quantitative, and each approach being conducted concurrently (Johnson \& Christensen, 2010). This mixed research design will help discover more about the school culture at the 10 Title I campuses, through the viewpoint of the faculty and staff who work there. The researchers will be certain to remain neutral while interviewing participants. Furthermore, results of similar studies will be researched and compared to the discoveries of this study.

\section{Limitations}

Threats to legitimation. First, according to Onwuegbuzie and Leech (2007), internal credibility includes conclusions made within a setting or group, such as the truth value, applicability, consistency, neutrality, dependability, and/or credibility of explanations. Threats to internal credibility for our study include descriptive validity, reactivity, and researcher bias. Descriptive validity includes the researchers accurately documenting each participant's words or views. This will be minimized by member checking, the process of systematically receiving feedback about conclusions made from the study group (Onwuegbuzie \& Leech, 2007). Furthermore, participants might be uncomfortable sharing truthful information with a researcher they do not know during the interview. This might be due to reactivity, changes that take place in participants when they know they are being observed (Johnson \& Christensen, 2010). During interviews, participants also might exhibit frontstage behavior. This consists of participants acting differently than normal, displaying behaviors they want the researcher to see when they know they are being observed by the interviewer (Johnson \& Christensen, 2010). This threat will be minimized by the researchers clearly explaining the purpose of the study and reminding the participants that their responses will be completely confidential and anonymous. To continue, researcher bias, involving personal assumptions of the researchers, might be evident to the participants and ultimately influence their attitudes, behaviors, or experiences (Onwuegbuzie \& Leech, 2007). Onwuegbuzie and Leech (2007) mention that research bias can be minimized by using unobtrusive measures, explaining the intentions of the researcher, carrying out interviews in a neutral place, and keeping a clear focus on the research questions.

On a different note, external credibility involves the ability to generalize findings of a study to various populations including different people, settings, and times (Onwuegbuzie \& Leech, 2007). Threats to external credibility include interpretative validity, researcher bias, reactivity, and order bias. Onwuegbuzie and Leech (2007) explained that interpretative validity is the 
accuracy that researchers have in correctly displaying the perspective of the participants and the meanings of their words and actions. This should be reduced by member checking, as explained before. Researcher bias, mentioned previously, also is an external threat, because the researchers' bias might hinder the data interpretation, making it ungeneralizable. Peer debriefing, the process of obtaining an external view of the research process, will be carried out to decrease bias (Onwuegbuzie \& Leech, 2007). Reactivity, also mentioned previously, threatens the generalizability of the findings, because it will not be known if the same results will be obtained if this threat did not take place. Finally, order bias, the order in which components are carried out, might make a difference to the findings. Also, more variables might be related to school culture than what the questions asked cover. This threat will be minimized by triangulation, the process of implementing various methods and sources to obtain data (Onwuegbuzie \& Leech, 2007).

Concerning mixed methods legitimation, inside-outside legitimation might cause differences in the research. According to Onwuegbuzie and Johnson (2006), this type of legitimation involves the researcher accurately portraying inside and outside views. The correct representation of the inside view will be checked by implementing participant review. This involves participants assessing the researcher's interpretations (Onwuegbuzie \& Johnson, 2006). The outside view will be checked by using peer review, the process of having an outside researcher not involved in the actual research, examine interpretations and conclusions (Onwuegbuzie \& Johnson, 2006). Furthermore, conversion legitimation might play a role in research results. Onwuegbuzie and Johnson (2006) state that this type of legitimation involves the degree to which quantizing (i.e., converting quantitative data into qualitative data; Johnson \& Christensen, 2010) and/or qualitizing (i.e., converting qualitative data into quantitative data; Johnson \& Christensen, 2010) data provides interpretable data and large inference quality. Lastly, multiple validities legitimation involves the degree all research studies are employed and the research can be viewed high on the multiple validities (Onwuegbuzie \& Johnson, 2006). In other words, all of the validities in the quantitative and qualitative components of the researched are addressed and achieved. This will be minimized by the researchers previously identifying the validities in each of the quantitative and qualitative components as well as methods to decrease them.

\section{Analysis}

Method of analysis. Concerning qualitative data collected, which will include interview responses and the open-ended responses gathered through the intramethod questionnaire, a constant comparison analysis will be implemented. Leech and Onwuegbuzie (2008) stated that a constant comparison analysis will allow the researchers to create theories or a set of themes from data gathered. This approach will involve coding each qualitative response. The data will be broken down into segments and given a code that describes each segment. Next, the codes will be grouped into similar categories and themes will be formed (Leech \& Onwuegbuzie, 2008).

Regarding the quantitative data obtained through the eight Likert-format items on the questionnaire, the mean, median, mode, and range will be calculated on responses for each 
item. These figures will be used to support the findings of the qualitative portion of the research. Furthermore, the numerical data collected also will be qualitized. This involves converting quantitative data into qualitative data (Johnson \& Christensen, 2010). The researchers will describe the findings of each question in words.

Each of the six researchers will be trained the exact same way in coding, and will participate in coding each of the interviews. Findings will be compared to assure intercoder reliability. This reliability involves consistency among various coders (Johnson \& Christensen, 2010). A posteriori codes (i.e., codes based on the data) will be implemented, and the data analysis will be exploratory in nature. This bottom-up or theory-generation approach will allow the researchers fully to compare their findings.

\section{References}

Ayers, W. (Ed.). (1995). To become a teacher: Making a difference in children's lives. New York, NY: Teacher College Press.

Bryan, J., \& Henry, L. (2008). Strengths-based partnerships: A school-family-community partnership approach to empowering students. Professional School Counseling, 12, 149-155. http://dx.doi.org/10.5330/PSC.n.2010-12.149

Daresh, J. C. (2007). Supervision as proactive leadership. (4th ed.) Prospect Heights, IL: Waveland Press.

Deal, T. E., \& Peterson, K. D. (1990). The principal's role in shaping school culture. Washington DC: U.S. Department of Education.

Engels, N., Hotton, G., Devos, G., Bouckenooghe, D., \& Aelterman, A. (2008). Principals in schools with a positive school culture. Educational Studies, 34, 159-174. http://dx.doi.org/10.1080/03055690701811263

Gilem, J. A. \& Gilem, R. R. (2003, October). Calculating, interpreting, and reporting Cronbach's alpha reliability coefficient for Likert-type scales. Paper presented at the Midwest Research to Practice Conference in Adult, Continuing, and Community Education. Retrieved from https://scholarworks.iupui.edu/bitstream/handle/1805/344/Gliem+\&+Gliem.pdf?sequenc $\mathrm{e}=1$

Henderson, C. L., Buehler, A. E., Stein, W. L., Dalton, J. E., Robinson, T. R., \& Anfara, V. A. (2005). Organizational health and student achievement in Tennessee middle level $\begin{array}{llll}\text { schools. } & \text { NASSP } & \text { Bulletin, } & \text { 89(644), }\end{array}$ http://dx.doi.org/10.1177/019263650508964404

Howley, A., Woodrum, A., Burgess, L., \& Rhodes, M. (2009). Planning for culturally responsive leadership: Insights from a study of principals of exemplary schools. Educational Planning, 18(2), 12-24. 
Johnson, R. B., \& Christensen, L. B. (2010). Educational research: Quantitative, qualitative, and mixed approaches (4th ed.). Thousand Oaks, CA: Sage.

Johnson, R. B., \& Onwuegbuzie, A. J. (2004). Mixed methods research: A research paradigm whose time has come. Educational Researcher, 33(7), 14-26. http://dx.doi.org/10.3102/0013189X033007014

Johnson, W. L., Snyder, K. J., Anderson, R. H., \& Johnson, A. M. (1996). School work culture and productivity. The Journal of Experimental Education, 64, 139-156. http://dx.doi.org/10.1080/00220973.1996.9943800

Keiser, K. A., \& Schulte, L. E. (2009). Seeking the sense of community: A comparison of two elementary schools' ethical climates. The School Community Journal, 19(2), 45-56.

Kelley, R.C., Thornton, B., \& Daugherty, R. (2005). Relationships between measures of leadership and school climate. Education, 126(1), 17-23.

Leech, N. L., \& Onwuegbuzie, A. J. (2008). Qualitative data analysis: A compendium of techniques and a framework for selection for school psychology research and beyond. School Psychology Quarterly, 23, 587-604. http://dx.doi.org/10.1037/1045-3830.23.4.587

Lester, F. (2005). On the theoretical, conceptual, and philosophical foundations for research in mathematics education. ZDM, 37, 457-467. http://dx.doi.org/10.1007/BF02655854

Lezotte, L. W. (1991). Correlates of effective schools: The first and second generation. Okemos, MI: Effective Schools Products, Ltd.

Lunenburg, F. C., \& Ornstein, A. C. (2008). Educational administration: Concepts and practices. Belmont, CA: Wadsworth Cengage Learning.

Macneil, A. J., Prater, D. L., \& Busch, S. (2009). The effects of school culture and climate on student achievement. International Journal of Leadership in Education, 12(1), 73-84. http://dx.doi.org/10.1080/13603120701576241

Onwuegbuzie, A. J., \& Collins, K. M. T. (2007). A typology of mixed methods sampling designs in social science research. The Qualitative Report, 12, 281-316. Retrieved from http://www.nova.edu/ssss/QR/QR12-2/onwuegbuzie2.pdf

Onwuegbuzie, A. J., \& Johnson, R. B. (2006). The validity issue in mixed research. Research in the Schools, 13(1), 48-63.

Onwuegbuzie, A. J., \& Leech, N. L. (2007). Validity and qualitative research: An oxymoron? Quality \& Quantity: International Journal of Methodology, 41, 233-249. http://dx.doi.org/10.1007/s11135-006-9000-3

Sergiovanni, T. J. (1984). Leadership and excellence in schooling. Educational Leadership, 41(5), 4-13.

Southworth, G., \& Du Quesnay, H. (2005). School leadership and system leadership. The 


\section{Al Macrothink}

International Journal of Education

ISSN 1948-5476

2012, Vol. 4, No. 2

Educational Forum, 69, 212-220. http://dx.doi.org/10.1080/00131720508984685

Texas Education Agency. (2010). Accountability manual. Retrieved from the Texas Education Agency website:http://ritter.tea.state.tx.us/perfreport/account/2010/manual/

Trochim, W. M. (2006). Research methods knowledge base: Types of reliability. Retrieved from http://www.socialresearchmethods.net/kb/reltypes.php

U.S. Department of Education. (n.d.a). Improving basic programs operated by local educational agencies. Retrieved from the US Department of Education website: http://www2.ed.gov/programs/titleiparta/index.html

U.S. Department of Education. (n.d.b). Title I- Improving the academic achievement of the disadvantaged. Retrieved from the US Department of Education website: http://www2.ed.gov/policy/elsec/leg/esea02/pg1.html\#sec1001 


\section{Mll Macrothink}

Appendix B

Part I and Part II Mixed Methods Research Proposal Scoring Rubric

\section{PART 1: SCORING CHECKLIST FOR CONTENT IN MIXED RESEARCH REPORTS}

Name:

Semester:

Date:

\section{DIRECTIONS:}

For each of the following statements, indicate the extent to which you agree or disagree to the corresponding ratings of students, according to the scale below. (Note: Any statements which are not applicable will automatically receive a Astrongly agree@ rating.)

$1=$ strongly disagree $\quad 2=$ disagree $\quad 3=$ neutral $\quad 4=$ agree $\quad 5=$ strongly agree

\section{CONTENT}

Title:

1. The title makes clear the population of interest.

$\begin{array}{lllll}1 & 2 & 3 & 4 & 5\end{array}$

2. The title makes clear the primary independent variable(s).

$\begin{array}{lllll}1 & 2 & 3 & 4 & 5\end{array}$

3. The title makes clear the dependent variable(s).

$\begin{array}{lllll}1 & 2 & 3 & 4 & 5\end{array}$

4. The title indicates the specific relationship between the major variables.

5. Vague, ambiguous, and emotional-laden terms have been avoided.

$\begin{array}{lllll}1 & 2 & 3 & 4 & 5\end{array}$

\section{Introduction/Literature Review:}

6. An explicit statement of the problem is present.

7. The statement of the problem is stated in the opening paragraph.

8. Adequate background information is given on the problem presented.

9. All background information given on the problem is relevant.

10. The statement of the problem leads smoothly to the next paragraph.

11. Quotations are avoided, and are only used when paraphrasing would lead to a loss of meaning or representation.

12. Every statement of fact is supported by one or more citations.

13. All findings from previous research are supported by one or more citations.

14. The literature review is comprehensive (i.e., the review contains at least

20 citations that are complete and exactly consistent with the citations presented in the reference list).

15. All references cited are relevant to the problem under investigation.

16. All or almost all of the sources are primary.

$\begin{array}{lllll}1 & 2 & 3 & 4 & 5\end{array}$

17. Most of the references are current.

$\begin{array}{lllll}1 & 2 & 3 & 4 & 5\end{array}$

18. The review explicitly relates previous studies to the problem.

$\begin{array}{lllll}1 & 2 & 3 & 4 & 5\end{array}$

19. The literature review section contains an appropriate number of

$\begin{array}{lllll}1 & 2 & 3 & 4 & 5\end{array}$ 


\section{MIN Macrothink}

subheadings.

20. Each subheading is reflective of the text contained within it.

21. At least some of the references have been critically analyzed.

$\begin{array}{lllll}1 & 2 & 3 & 4 & 5\end{array}$

22. The references have been compared and contrasted adequately.

$\begin{array}{lllll}1 & 2 & 3 & 4 & 5\end{array}$

23. The review logically flows in such a way that the references least related

$\begin{array}{lllll}1 & 2 & 3 & 4 & 5\end{array}$

to the problem are discussed first and the most related references are discussed last.

24. Clear connections are made between the present study and the previous research.

25. All conceptual/theoretical terms are directly/operationally defined.

26. A clear conceptual/theoretical framework is presented.

$\begin{array}{lllll}1 & 2 & 3 & 4 & 5\end{array}$

27. The conceptual/theoretical framework is associated with one or more appropriate citations.

28. The gap in the literature is clearly identified.

$\begin{array}{lllll}1 & 2 & 3 & 4 & 5\end{array}$

29 . The review concludes with a brief summary.

$\begin{array}{lllll}1 & 2 & 3 & 4 & 5\end{array}$

30. The summary is an adequate representation of material that was

$\begin{array}{lllll}1 & 2 & 3 & 4 & 5\end{array}$ presented previously.

31. The summary does not contain new information that should have been introduced earlier.

32. A clear rationale for the study is provided.

33. There is an explicit purpose statement.

34. The purpose statement flows logically from the rationale.

35. The purpose statement makes clear the population of interest.

36. The purpose statement makes clear the primary dependent variable.

$\begin{array}{lllll}1 & 2 & 3 & 4 & 5\end{array}$

$\begin{array}{lllll}1 & 2 & 3 & 4 & 5\end{array}$

$\begin{array}{lllll}1 & 2 & 3 & 4 & 5\end{array}$

37. The purpose statement indicates the specific relationship between the

$\begin{array}{lllll}1 & 2 & 3 & 4 & 5\end{array}$

$\begin{array}{lllll}1 & 2 & 3 & 4 & 5\end{array}$

major cases/variables.

38. The purpose statement is consistent with the title.

$\begin{array}{lllll}1 & 2 & 3 & 4 & 5\end{array}$

39. The research problem is researchable.

40. One or more explicit research questions are presented.

41. The research questions follow the purpose statement.

42. Each research question makes clear the population of interest.

$\begin{array}{lllll}1 & 2 & 3 & 4 & 5\end{array}$

$\begin{array}{lllll}1 & 2 & 3 & 4 & 5\end{array}$

$\begin{array}{lllll}1 & 2 & 3 & 4 & 5\end{array}$

$\begin{array}{lllll}1 & 2 & 3 & 4 & 5\end{array}$

43. Each research question makes clear the primary independent variable.

$\begin{array}{lllll}1 & 2 & 3 & 4 & 5\end{array}$

44. Each research question makes clear the primary dependent variable.

$\begin{array}{lllll}1 & 2 & 3 & 4 & 5\end{array}$

45. Each hypothesis is stated clearly and concisely.

$\begin{array}{lllll}1 & 2 & 3 & 4 & 5\end{array}$

46. In each research hypothesis, the expected relationship or difference is

$\begin{array}{lllll}1 & 2 & 3 & 4 & 5\end{array}$ clear.

47. Each hypothesis makes clear the population of interest.

48. Each hypothesis makes clear the primary independent variable.

$\begin{array}{lllll}1 & 2 & 3 & 4 & 5\end{array}$

49. Each hypothesis makes clear the primary dependent variable.

$\begin{array}{lllll}1 & 2 & 3 & 4 & 5\end{array}$

50. Each hypothesis logically flows from the theoretical framework.

51. Each hypothesis is testable.

$\begin{array}{lllll}1 & 2 & 3 & 4 & 5\end{array}$

$\begin{array}{lllll}1 & 2 & 3 & 4 & 5\end{array}$

52. The educational significance is stated explicitly.

$\begin{array}{lllll}1 & 2 & 3 & 4 & 5\end{array}$

53. This section is well-integrated (i.e., flows well).

$\begin{array}{lllll}1 & 2 & 3 & 4 & 5\end{array}$

$\begin{array}{lllll}1 & 2 & 3 & 4 & 5\end{array}$ 
54. Vague, ambiguous, and emotional-laden terms have been avoided. 2012, Vol. 4, No. 2

\section{Method}

\section{Participants for Quantitative Sample/Phase}

55. The (approximate) population size is provided.

$\begin{array}{lllll}1 & 2 & 3 & 4 & 5\end{array}$

56. The major characteristics of the population are described adequately.

$\begin{array}{lllll}1 & 2 & 3 & 4 & 5\end{array}$

57. The selection-eligibility criteria are described adequately.

$\begin{array}{lllll}1 & 2 & 3 & 4 & 5\end{array}$

58. If a sample was selected, at least one of the 24 sampling schemes

$\begin{array}{lllll}1 & 2 & 3 & 4 & 5\end{array}$

identified by Onwuegbuzie and Collins (2007) is specified accurately.

59. If a sample was selected, the sampling scheme is described

$\begin{array}{lllll}1 & 2 & 3 & 4 & 5\end{array}$ clearly and accurately.

60. An adequate rationale is provided for choice of sampling scheme.

61. The (approximate) sample size and group sizes are provided.

$\begin{array}{lllll}1 & 2 & 3 & 4 & 5\end{array}$

62. The sample size and group sizes are adequate for the research design.

$\begin{array}{lllll}1 & 2 & 3 & 4 & 5\end{array}$

63 . The sample size is consistent with the type of generalization suggested by the title, purpose statement, and research question.

64. The major characteristics of the sample are described adequately.

65 . Evidence of ethical considerations is provided adequately.

66. This section is well-integrated (i.e., flows well).

67. Vague, ambiguous, and emotional-laden terms have been avoided.

$\begin{array}{lllll}1 & 2 & 3 & 4 & 5\end{array}$

\section{Participants for Qualitative Sample/Phase}

68. The setting is described adequately.

69. The (approximate) population size is provided.

$\begin{array}{lllll}1 & 2 & 3 & 4 & 5\end{array}$

70. The major characteristics of the population are described adequately.

$\begin{array}{lllll}1 & 2 & 3 & 4 & 5\end{array}$

71. The selection-eligibility criteria are described adequately.

$\begin{array}{lllll}1 & 2 & 3 & 4 & 5\end{array}$

$\begin{array}{lllll}1 & 2 & 3 & 4 & 5\end{array}$

$\begin{array}{lllll}1 & 2 & 3 & 4 & 5\end{array}$

$\begin{array}{lllll}1 & 2 & 3 & 4 & 5\end{array}$

72. If a sample will be selected, at least of the 24 sampling schemes identified by Onwuegbuzie and Collins (2007) is specified accurately.

73. If a sample will be selected, the sampling scheme is described clearly $1 \begin{array}{llllll}1 & 2 & 3 & 4 & 5\end{array}$ and accurately.

74. An adequate rationale is provided for choice of sampling scheme.

75. Evidence is presented that the sample of words/observations (i.e., sample space) will represent the population of words/observations (i.e., truth space) for the underlying context.

76. The (approximate) sample size and group sizes are provided.

77. An adequate rationale is provided for the sample size/group sizes.

$\begin{array}{lllll}1 & 2 & 3 & 4 & 5\end{array}$

78. The sample size and group sizes are adequate for the research design.

$\begin{array}{lllll}1 & 2 & 3 & 4 & 5\end{array}$

79. The sample size is consistent with the type of generalization suggested

$\begin{array}{lllll}1 & 2 & 3 & 4 & 5\end{array}$

by the title, purpose statement, and research question.

80. The major characteristics of the sample are described adequately.

$\begin{array}{lllll}1 & 2 & 3 & 4 & 5\end{array}$

81. The relationship of the researcher to the participants are fully described

$\begin{array}{lllll}1 & 2 & 3 & 4 & 5\end{array}$

(e.g., participant observer, non-participant observer, collaborator).

82. The role of the researcher is described clearly (e.g., neutral, $1 \quad 2 \quad 3 \quad 4 \quad 5$ 
collaborative, objective).

83. Evidence of ethical considerations is provided adequately.

84. This section of the proposal is well-integrated (i.e., flows well).

$\begin{array}{lllll}1 & 2 & 3 & 4 & 5\end{array}$

85. Vague, ambiguous, and emotional-laden terms have been avoided.

$\begin{array}{lllll}1 & 2 & 3 & 4 & 5\end{array}$

\section{Mixed Sampling Design}

86. The mixed sampling design is provided using Onwuegbuzie and $1 \quad 2 \quad 3 \quad 4 \quad 5$ Collins's (2007) framework.

87. The time orientation (i.e., sequential vs. concurrent) for selecting the $\begin{array}{llllll}1 & 2 & 3 & 4 & 5\end{array}$ quantitative and qualitative samples is specified clearly.

88. The time orientation (i.e., sequential vs. concurrent) for selecting the $\begin{array}{llllll}1 & 2 & 3 & 4 & 5\end{array}$ quantitative and qualitative samples is described clearly.

89. The relationship of the quantitative and qualitative samples (i.e., $1122 \quad 3 \quad 4 \quad 5$ identical, parallel, nested, multilevel) is specified clearly.

90. The relationship of the quantitative and qualitative samples (i.e., $1122 \quad 3 \quad 4 \quad 5$ identical, parallel, nested, multilevel) is described clearly

91. This section of the report is well-integrated (i.e., flows well).

92. Vague, ambiguous, and emotional-laden terms have been avoided.

$\begin{array}{lllll}1 & 2 & 3 & 4 & 5\end{array}$

$\begin{array}{lllll}1 & 2 & 3 & 4 & 5\end{array}$

\section{Instruments for Quantitative Phase}

93. An adequate rationale is given for the selection of each instrument.

$\begin{array}{lllll}1 & 2 & 3 & 4 & 5\end{array}$

94. Each instrument is described adequately in terms of purpose and content.

$\begin{array}{lllll}1 & 2 & 3 & 4 & 5\end{array}$

95. The developers of all instruments are specified clearly.

$\begin{array}{lllll}1 & 2 & 3 & 4 & 5\end{array}$

96. The format of the items is specified clearly and accurately.

$\begin{array}{lllll}1 & 2 & 3 & 4 & 5\end{array}$

97. The administration, scoring or tabulating, and interpretation. procedures

$\begin{array}{lllll}1 & 2 & 3 & 4 & 5\end{array}$

are fully described.

98. Citations are presented for any information provided pertaining to the $\begin{array}{llllll}1 & 2 & 3 & 4 & 5\end{array}$ development of all instruments (e.g., standardization/norming techniques).

99. Citations are provided for all statements of facts and research findings $\quad \begin{array}{llllll}1 & 2 & 3 & 4 & 5\end{array}$ pertaining to the characteristics of the instruments.

100. Each instrument appears to be appropriate for measuring the intended $1122 \quad 3 \quad 4 \quad 5$ variables.

101. Evidence is given that each instrument was appropriate for the sample. $\quad \begin{array}{llllll}1 & 2 & 3 & 4 & 5\end{array}$

102. Each instrument appears to be appropriate for the sample under study. $\begin{array}{lllllll}1 & 2 & 3 & 4 & 5\end{array}$

103. Adequate information is provided which indicates that administrators, $11 \quad 2 \quad 3 \quad 3 \quad 4 \quad 5$ observers, or interviewers were well trained.

104. Adequate information is provided which indicates that there was no $11 \quad 2 \quad 3 \quad 4 \quad 4 \quad 5$ administrator, observer, or interviewer effect.

105. Instrument score reliability presented by the developer is described $1120 \begin{array}{lllll} & 2 & 4 & 5\end{array}$ adequately in terms of type of coefficients.

106. Instrument score reliability presented by the developer is described $1123 \quad 3 \quad 4 \quad 5$ adequately in terms of size of coefficients.

107. If appropriate, subtest score reliabilities presented by the developer are $\quad \begin{array}{llllll}1 & 2 & 3 & 4 & 5\end{array}$ 
provided adequately.

108. If no information on score reliability was available in the literature, this $\begin{array}{llllll}1 & 2 & 3 & 4 & 5\end{array}$ is specified clearly.

109. Instrument score reliability that was computed by the researcher is $\begin{array}{lllllll}1 & 2 & 3 & 4 & 5\end{array}$ described adequately in terms of type of coefficients.

110. Instrument score reliability that was computed by the researcher is $\begin{array}{lllllll}1 & 2 & 3 & 4 & 5\end{array}$ described adequately in terms of size of coefficients.

111. Instrument score reliability that was computed by the researcher is $\begin{array}{llllll}1 & 2 & 3 & 4 & 5\end{array}$ described adequately in terms of the purpose of coefficients.

112. All instruments used appear that they yielded scores that were $1 \quad 2 \quad 3 \quad 4 \quad 5$ sufficiently reliable.

113. Citations are provided for all reliability coefficients presented. $\quad \begin{array}{llllll} & 2 & 3 & 4 & 5\end{array}$ 114. Instrument score validity is discussed and coefficients given if $1120 \begin{array}{llllll} & 2 & 4 & 5\end{array}$ appropriate.

115. Each instrument is described in terms of content-related validity.

116. Each instrument is described in terms of criterion-related validity.

117. Each instrument is described in terms of construct-related validity.

$\begin{array}{lllll}1 & 2 & 3 & 4 & 5\end{array}$

$\begin{array}{lllll}1 & 2 & 3 & 4 & 5\end{array}$

118. If no information on content-, criterion-, and/or construct-related $\begin{array}{lllll}1 & 2 & 3 & 4 & 5\end{array}$ validity was available in the literature, this is specified clearly.

119. All instruments used appear that they yielded scores that were $1 \begin{array}{llllll} & 2 & 3 & 4 & 5\end{array}$ sufficiently valid for the study.

120. Citations are provided for all validity coefficients presented.

121. If an instrument was designed specifically for the study, the procedures involved in its development are described adequately.

122. If an instrument was designed specifically for the study, the procedures $\quad 1 \quad 2 \quad \begin{array}{lllll}3 & 4 & 5\end{array}$ involved in its score validation are described adequately.

123. If an instrument was designed specifically for the study, the $\begin{array}{lllllll} & 2 & 3 & 4 & 5\end{array}$ administration, scoring or tabulating, and interpretation procedures are fully described.

124. This section is well-integrated (i.e., flows well).

$\begin{array}{lllll}1 & 2 & 3 & 4 & 5\end{array}$

125. Vague, ambiguous, and emotional-laden terms have been avoided.

$\begin{array}{lllll}1 & 2 & 3 & 4 & 5\end{array}$

\section{Instruments for Qualitative Phase}

126. An adequate rationale is given for the selection of each instrument. $\quad \begin{array}{llllll}1 & 2 & 3 & 4 & 5\end{array}$ 127. Each instrument is described adequately in terms of purpose and $1 \begin{array}{lllll}1 & 2 & 3 & 4 & 5\end{array}$ content.

128. The developers of all instruments are specified clearly. $\quad \begin{array}{lllll}1 & 2 & 3 & 4 & 5\end{array}$

129. The format of the items (e.g., open-ended) is specified clearly and $11 \quad 2 \quad 3 \quad 4 \quad 4 \quad 5$ accurately.

130. Citations are provided for all statements of facts and research findings $\quad 1 \quad 2 \quad 3 \quad 3 \quad 4 \quad 5$ pertaining to the characteristics of the instruments.

131. Each instrument appears to be appropriate for measuring the intended $\quad 1 \quad 2 \quad 3 \quad 3 \quad 4 \quad 5$ phenomenon/variables. 
132. Evidence is given that each instrument is appropriate for the sample. $\quad \begin{array}{llllll}1 & 2 & 3 & 4 & 5\end{array}$

133. Each instrument appears to be appropriate for the sample under study. $\quad \begin{array}{llllll}1 & 2 & 3 & 4 & 5\end{array}$ 134. Adequate information is provided which indicates that administrators, $11 \quad 2 \quad 3 \quad 3 \quad 4 \quad 5$ observers, or interviewers are/will be well trained.

135. If an instrument was/will be designed specifically for the study, the $\begin{array}{llllll}1 & 2 & 3 & 4 & 5\end{array}$ procedures involved in its development are described adequately.

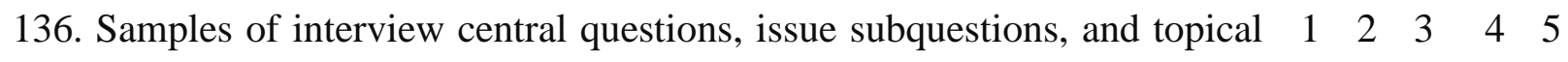
subquestions are provided.

137. Interview questions/subquestions are described as basic descriptive, $\begin{array}{llllll}1 & 2 & 3 & 4 & 5\end{array}$ follow-up, experience/example, simple clarification, structural/paradigmatic, and comparison/contrast (Janesick, 2004).

138. Type of interview is specified (e.g., unstructured, partially structured, $11 \quad 2 \quad 3 \quad 4 \quad 4 \quad 5$ semi-structured, structured, totally structured).

139. All interviewers are identified clearly.

140. Location of interview is specified (i.e., interviewee's workplace).

141. Length of interview is specified (i.e., short vs. long).

$\begin{array}{lllll}1 & 2 & 3 & 4 & 5\end{array}$

142. Estimated number of interviews is specified (e.g., single vs. multiple).

$\begin{array}{lllll}1 & 2 & 3 & 4 & 5\end{array}$

$\begin{array}{lllll}1 & 2 & 3 & 4 & 5\end{array}$

143. Format of interviews is specified (e.g., formal vs. informal).

$\begin{array}{lllll}1 & 2 & 3 & 4 & 5\end{array}$

144. Samples of focus group questions are provided.

145. Samples of probes to questions are provided.

$\begin{array}{lllll}1 & 2 & 3 & 4 & 5\end{array}$

$\begin{array}{lllll}1 & 2 & 3 & 4 & 5\end{array}$

146. All observational data collection techniques are described adequately.

$\begin{array}{lllll}1 & 2 & 3 & 4 & 5\end{array}$

147. All observation protocols used (e.g., Flanders, 1965) are described $1120 \begin{array}{lllll} & 2 & 4 & 5\end{array}$ adequately.

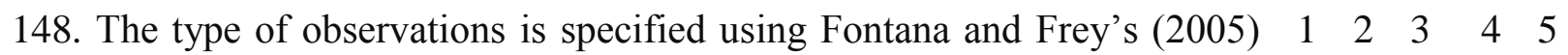
categorization (i.e., kinesic, proxemic, chronemic, paralinguistic) .

149. Observer is classified as peripheral member, active member, or $\begin{array}{llllll}1 & 2 & 3 & 4 & 5\end{array}$ complete member (Adler \& Adler, 1987).

150. Observation is classified as descriptive observation, focus observation, $\begin{array}{llllll}1 & 2 & 3 & 4 & 5\end{array}$ or selective observation (Werner \& Schoepfle, 1987).

151. All documents that will be analyzed are identified clearly.

$\begin{array}{lllll}1 & 2 & 3 & 4 & 5\end{array}$

152. This section of the proposal is well-integrated (i.e., flows well).

$\begin{array}{lllll}1 & 2 & 3 & 4 & 5\end{array}$

153. Vague, ambiguous, and emotional-laden terms have been avoided.

$\begin{array}{lllll}1 & 2 & 3 & 4 & 5\end{array}$

\section{Procedure for the Quantitative Phase}

154. All data collecting procedures are clearly described.

$\begin{array}{lllll}1 & 2 & 3 & 4 & 5\end{array}$

155. The study was conducted for an appropriate length of time for the $\begin{array}{llllllll}1 & 2 & 3 & 4 & 5\end{array}$ predicted outcomes to be observed.

156. The training of data collectors is clearly described and adequate. $\quad \begin{array}{llllll}1 & 2 & 3 & 4 & 5\end{array}$

157. It appears that the data collection procedure was conducted in a $1 \begin{array}{lllllll} & 2 & 3 & 4 & 5\end{array}$ consistent manner.

158. The ethical nature of data collection method is discussed adequately. $\quad \begin{array}{llllll} & 1 & 2 & 3 & 4 & 5\end{array}$

159. Procedures are described in sufficient detail to permit replication. $\quad \begin{array}{lllllll}1 & 2 & 3 & 4 & 5\end{array}$

160. Citations are provided for any procedural information delineated which $\begin{array}{llllll}1 & 2 & 3 & 4 & 5\end{array}$ 
are directly or indirectly based on previous research.

161. If a pilot study was conducted, its purpose is described adequately, as well as its impact on the subsequent study.

162. The procedures provide sufficient control for internal validity.

163. The procedures provide sufficient control for external validity.

164. The research paradigm used is clear.

165. The research design is stated clearly and accurately.

166. Adequate justification is provided for the research design used.

167. Citations are provided when describing the research design used.

$\begin{array}{lllll}1 & 2 & 3 & 4 & 5\end{array}$

168. The design appears to be appropriate for answering the research question and/or testing the hypothesis.

169. If treatment groups were compared, it is clear whether participants were $\quad \begin{array}{llllll}1 & 2 & 3 & 4 & 5\end{array}$ randomly assigned to groups.

170. If treatment groups were compared, the number of participants in each $\quad \begin{array}{llllll}1 & 2 & 3 & 4 & 5\end{array}$ group was stated.

171. If treatment groups were compared, the number of participants per group used appears to be adequate, or else an appropriate rationale is provided as to why the group sizes were smaller than recommended.

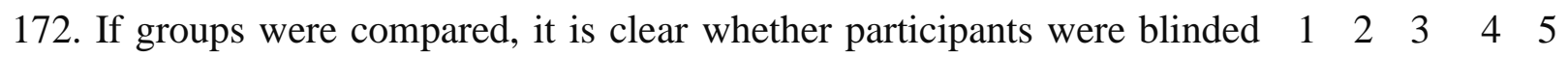
as to what treatment group they were assigned.

173. If groups were compared, it is clear whether the individual measuring the outcome variable(s) was blinded to the treatment group to which the participants were assigned.

174. If groups were compared and participants were aware of their group assignment, it is clear whether this knowledge affected their responses.

175. If groups were compared and the individual measuring the outcome variable was not blinded, it is clear that the measurements were not biased by this.

176. If groups were compared, the conditions of all experimental groups are described clearly and completely.

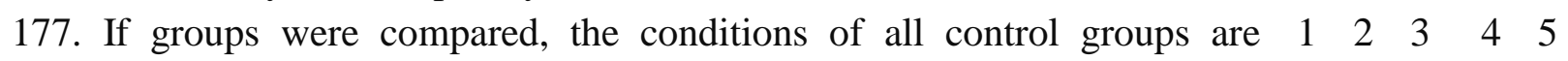
described clearly and completely.

178. If groups were compared, participants in all groups received the exact

$\begin{array}{lllll}1 & 2 & 3 & 4 & 5\end{array}$

$\begin{array}{lllll}1 & 2 & 3 & 4 & 5\end{array}$

$\begin{array}{lllll}1 & 2 & 3 & 4 & 5\end{array}$

$\begin{array}{lllll}1 & 2 & 3 & 4 & 5\end{array}$

$\begin{array}{lllll}1 & 2 & 3 & 4 & 5\end{array}$

$\begin{array}{lllll}1 & 2 & 3 & 4 & 5\end{array}$

$\begin{array}{lllll}1 & 2 & 3 & 4 & 5\end{array}$

15

$\begin{array}{lllll}1 & 2 & 3 & 4 & 5\end{array}$

same experimental procedures and measurements, except for the treatment intervention.

179. If groups were compared, it is clear that there was strict adherence to the protocol in all groups.

180. If groups were compared, any participant attrition is described clearly.

$\begin{array}{lllll}1 & 2 & 3 & 4 & 5\end{array}$

$\begin{array}{lllll}1 & 2 & 3 & 4 & 5\end{array}$

$\begin{array}{lllll}1 & 2 & 3 & 4 & 5\end{array}$

181. If groups were compared, it is clear whether any unexpected outcomes ensued.

182. This section is well-integrated (i.e., flows well).

183. Vague, ambiguous, and emotional-laden terms have been avoided.

$\begin{array}{lllll}1 & 2 & 3 & 4 & 5\end{array}$

$\begin{array}{lllll}1 & 2 & 3 & 4 & 5\end{array}$ 


\section{Procedure for the Qualitative Phase}

184. All data collecting procedures are clearly described.

$\begin{array}{lllll}1 & 2 & 3 & 4 & 5\end{array}$

185. The study will be conducted for an appropriate length of time for the

$\begin{array}{lllll}1 & 2 & 3 & 4 & 5\end{array}$
predicted outcomes to be observed.

187. The ethical nature of data collection method is discussed adequately.

186. The training of data collectors is clearly described and adequate.

$\begin{array}{lllll}1 & 2 & 3 & 4 & 5\end{array}$

188. The research paradigm used is clear.

$\begin{array}{lllll}1 & 2 & 3 & 4 & 5\end{array}$

189. The philosophical correlates of the research paradigm are specified

$\begin{array}{lllll}1 & 2 & 3 & 4 & 5\end{array}$

clearly (e.g., hermeneutics, post-positivist, post-structuralist, post-modernist, constructivist, feminist, idealist).

190. Citations are provided for selected correlates of research paradigm.

191. The assumption(s) of research paradigm are provided.

192. The research design is stated clearly and accurately.

193. If a case study design is used, the type of case study (i.e., instrumental,

$\begin{array}{llll}2 & 3 & 4 & 5\end{array}$

intrinsic, collective/multiple; Stake, 2005; Yin, 2004) is identified and described clearly.

194. If a phenomenological design is used, the type of phenomenology (i.e., $\quad 1 \quad 2 \quad 3 \quad 3 \quad 4 \quad 5$ reflective/transcendental, dialogical, empirical, existential, hermeneutic, social, psychological; Creswell, 2007) is identified and described clearly.

195. Adequate justification is provided for the research design used.

$\begin{array}{lllll}1 & 2 & 3 & 4 & 5\end{array}$

$\begin{array}{lllll}1 & 2 & 3 & 4 & 5\end{array}$

$\begin{array}{lllll}1 & 2 & 3 & 4 & 5\end{array}$

$\begin{array}{lllll}1 & 2 & 3 & 4 & 5\end{array}$

196. Information is provided about how the research design may evolve as the process unfolds.

197. Citations are provided when describing the research design used.

198. The design appears to be appropriate for answering the research question and/or testing the hypothesis.

199. Evidence is provided that the researcher will not be the sole voice of the $\begin{array}{lllll}1 & 2 & 3 & 4 & 5\end{array}$ participant.

200. Evidence is provided that any interviewers will not influence the $\begin{array}{llllll}1 & 2 & 3 & 4 & 5\end{array}$ content of the interviewee's/focus group's description in such a way that these descriptions do not truly affect the actual experience.

201. Evidence is provided that all transcripts will be accurate.

202. The form of all collected data is adequately described (e.g., field notes, $11 \quad 2 \quad 3 \quad 3 \quad 4 \quad 5$ audio tapes, videotapes, referential material).

203. Evidence is provided that rich data will be collected.

204. Evidence is provided that the data sources are well chosen.

$\begin{array}{lllll}1 & 2 & 3 & 4 & 5\end{array}$

205. Evidence is provided that the number of data sources is adequate.

$\begin{array}{lllll}1 & 2 & 3 & 4 & 5\end{array}$

206. Evidence is provided that data will be collected in a systematic manner.

$\begin{array}{lllll}1 & 2 & 3 & 4 & 5\end{array}$

207. It is described adequately how entry into the research context will be

$\begin{array}{lllll}1 & 2 & 3 & 4 & 5\end{array}$
obtained.

208. No important verification procedures are omitted.

209. This section of the proposal is well-integrated (i.e., flows well).

$\begin{array}{lllll}1 & 2 & 3 & 4 & 5\end{array}$

210. Vague, ambiguous, and emotional-laden terms have been avoided.

$\begin{array}{lllll}1 & 2 & 3 & 4 & 5\end{array}$

$\begin{array}{lllll}1 & 2 & 3 & 4 & 5\end{array}$ 


\section{Procedure for the Mixed Research Phase}

211. The rationale for conducting a mixed research study is stated clearly $\quad \begin{array}{llllll}1 & 2 & 3 & 4 & 5\end{array}$ (i.e., triangulation vs. complementarity vs. development vs. initiation vs. expansion; cf. Greene, Caracelli, \& Graham, 1989, which is discussed in the Johnson \& Christensen, 2010 text).

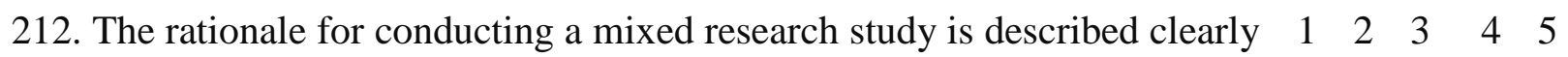
(i.e., triangulation vs. complementarity vs. development vs. initiation vs. expansion; cf. Greene, Caracelli, \& Graham, 1989, which is discussed in the Johnson \& Christensen, 2010 text).

213. The type of mixed research design is identified and labeled (cf. Johnson $\quad 1 \quad 2 \quad \begin{array}{llll}3 & 4 & 5\end{array}$ \& Christensen, 2010).

214. The type of mixed research design is described adequately (cf. Johnson $\quad 1 \quad \begin{array}{lllll}1 & 2 & 3 & 4 & 5\end{array}$ \& Christensen, 2010).

215. It is specified clearly whether a partially mixed or fully mixed research $\quad 1 \quad 2 \quad 2 \quad 3 \quad 4 \quad 45$ design is used (cf. Johnson \& Christensen, 2010).

216. It is specified clearly whether the mixed research design is sequential or $\quad \begin{array}{llllll}1 & 2 & 3 & 4 & 5\end{array}$ concurrent (cf. Johnson \& Christensen, 2010).

217. It is specified whether the quantitative or qualitative phase is dominant or whether there is approximately equal emphasis (cf. Johnson \& Christensen, 2010).

218. This section of the proposal is well-integrated (i.e., flows well).

219. Vague, ambiguous, and emotional-laden terms have been avoided.

$\begin{array}{lllll}1 & 2 & 3 & 4 & 5\end{array}$

$\begin{array}{lllll}1 & 2 & 3 & 4 & 5\end{array}$

\section{Limitations}

220. At least two possible threats to internal validity are discussed $1122 \quad 3 \quad 4 \quad 5$ adequately.

221. At least two possible threats to external validity are discussed $1122 \quad 3 \quad 4 \quad 5$ adequately.

222. Each threat to internal validity discussed is labeled appropriately.

223 . Each threat to external validity discussed is labeled appropriately.

224. Citations are provided when referring to threats to validity.

225. Discussion as to how to minimize each threat to internal validity is adequate.

226. Discussion as to how to minimize each threat to external validity is adequate.

227. All important threats to internal validity are discussed.

228. All important threats to external validity are discussed.

229. The discussion of threats to Verification/Trustworthiness/legitimation/

$\begin{array}{lllll}1 & 2 & 3 & 4 & 5\end{array}$

$\begin{array}{lllll}1 & 2 & 3 & 4 & 5\end{array}$

$\begin{array}{lllll}1 & 2 & 3 & 4 & 5\end{array}$

$\begin{array}{lllll}1 & 2 & 3 & 4 & 5\end{array}$

Authenticity/Credibility/Transferability/Dependability/Confirmability of data is adequately undertaken using a framework (e.g., Creswell, 2007; Creswell \& Miller, 1987; Guba \& Lincoln, 1989; Lather, 1991, 1993; LeCompte \& Goetz, 1982; Lincoln \& Guba, 1985; Miles \& Huberman, 1994).

230. Each legitimation threat discussed is labeled appropriately. 
231. Citations are provided when referring to threats to legitimation.

$\begin{array}{lllll}1 & 2 & 3 & 4 & 5\end{array}$

232. All important threats to legitimation are discussed.

$\begin{array}{lllll}1 & 2 & 3 & 4 & 5\end{array}$

233. At least one verification procedure is described in detail e.g., $1 \quad 2 \quad 3 \quad 4 \quad 5$ prolonged engagement, persistent observation, triangulation, contextualization of observations, method of constant comparison, checking for representativeness of sources of data, checking for researcher effects, weighing the evidence, examining extreme cases, checking for spurious relations, examining rival explanations, looking for negative evidence, obtaining feedback from informants, leaving an audit trail, thick description, assessing structural relationships, use of referential material, theoretical sampling; Onwuegbuzie \& Leech, 2007).

234. Citations are provided when referring to each verification procedure.

235. This section of the proposal is well-integrated (i.e., flows well).

236. Vague, ambiguous, and emotional-laden terms have been avoided.

$\begin{array}{lllll}1 & 2 & 3 & 4 & 5\end{array}$

$\begin{array}{lllll}1 & 2 & 3 & 4 & 5\end{array}$

$\begin{array}{lllll}1 & 2 & 3 & 4 & 5\end{array}$

\section{Analysis of Quantitative Data}

237. An adequate description is provided as to the analysis intended to $1122 \quad 3 \quad 4 \quad 5$ address the research question(s) and/or test the hypotheses.

238. All dependent variables are specified clearly.

$\begin{array}{lllll}1 & 2 & 3 & 4 & 5\end{array}$

239. The scale of measurement pertaining to each dependent variable is $\begin{array}{llllllll}1 & 2 & 3 & 4 & 5\end{array}$ presented clearly and accurately.

240. The dependent variables presented are consistent with the research $11 \quad 2 \quad 3 \quad 4 \quad 4 \quad 5$ questions/hypotheses.

241. All independent variables are specified clearly.

$\begin{array}{lllll}1 & 2 & 3 & 4 & 5\end{array}$

242. The scale of measurement pertaining to each independent variable $\quad$ is $\quad \begin{array}{lllllll} & 2 & 3 & 4 & 5\end{array}$ presented clearly and accurately.

243. The independent variables presented are consistent with the research $1122 \quad 3 \quad 4 \quad 5$ questions/hypotheses.

244. The method of analysis is appropriate for testing the research $1122 \quad 3 \quad 4 \quad 5$ hypothesis.

245. The method of analysis is for testing each research hypothesis is $\begin{array}{lllllll}1 & 2 & 3 & 4 & 5\end{array}$ presented.

246. The method of analysis is for testing each research hypothesis is $1 \begin{array}{lllll}1 & 2 & 3 & 4 & 5\end{array}$ consistent with the scales of measurements presented.

247. The significance level of the statistical tests is delineated, and $1 \quad 2 \quad 3 \quad 4 \quad 5$ appropriate control is made for Type 1 and Type II error.

248. All assumptions (e.g., linearity, independence, normality, homogeneity $11 \quad 2 \quad 3 \quad 4 \quad 4 \quad 5$ of variance) associated with the inferential test are described adequately and accurately.

249. Statistical power is discussed adequately.

250. Effect size(s) are discussed.

$\begin{array}{lllll}1 & 2 & 3 & 4 & 5\end{array}$

251. The type of effect size(s) (e.g., Cohen's (1988) d; R2, $\omega 2$ ) is delineated. 252. All statistical software are specified (e.g., SPSS, SAS, SYSTAT). 
253. Citations are provided for all statistical software identified. 2012, Vol. 4, No. 2

254. This section is well-integrated (i.e., flows well).

255. Vague, ambiguous, and emotional-laden terms have been avoided.

$\begin{array}{lllll}1 & 2 & 3 & 4 & 5 \\ 1 & 2 & 3 & 4 & 5 \\ 1 & 2 & 3 & 4 & 5\end{array}$

\section{Analysis of Qualitative Data}

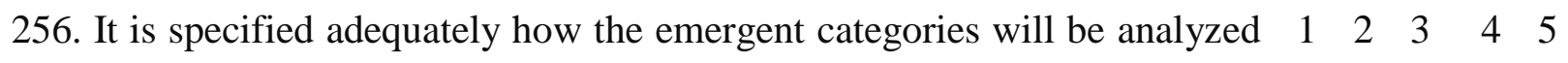
(e.g., method of constant comparison).

257. It is clear whether exploratory or confirmatory techniques (or both) will $\quad 1 \quad 2 \quad 2 \quad 3 \quad 4 \quad 5$ be used.

258. All qualitative software are specified (e.g., QDA Miner, NVIVO, $1122 \quad 3 \quad 4 \quad 5$ Atlas-ti, Ethnograph).

259. Citations are provided for all statistical software identified.

$\begin{array}{lllll}1 & 2 & 3 & 4 & 5\end{array}$

260. This section of the proposal is well-integrated (i.e., flows well).

261. Vague, ambiguous, and emotional-laden terms have been avoided.

$\begin{array}{lllll}1 & 2 & 3 & 4 & 5\end{array}$

$\begin{array}{lllll}1 & 2 & 3 & 4 & 5\end{array}$

\section{Mixed Analysis}

262 . The number of data types that will be analyzed is described clearly

$\begin{array}{lllll}1 & 2 & 3 & 4 & 5\end{array}$

263. The number of data analysis types that will be used is described clearly $\quad \begin{array}{lllllll}1 & 2 & 3 & 4 & 5\end{array}$

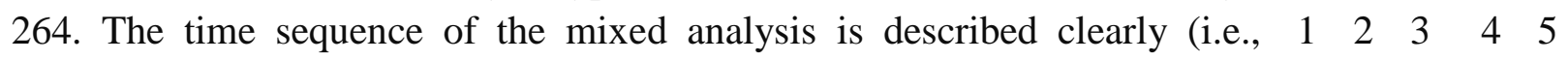
sequential vs. concurrent).

265. It is specified whether data were qualitized and/or quantitized.

$\begin{array}{lllll}1 & 2 & 3 & 4 & 5\end{array}$

266. If a sequential mixed analysis was used, the order of the mixed analysis

$\begin{array}{lllll}1 & 2 & 3 & 4 & 5\end{array}$

(e.g., quantitative analysis followed by qualitative analysis or qualitative analysis followed by quantitative analysis)

267. This section of the report is well-integrated (i.e., flows well).

$\begin{array}{lllll}1 & 2 & 3 & 4 & 5\end{array}$

268. Vague, ambiguous, and emotional-laden terms have been avoided.

$\begin{array}{lllll}1 & 2 & 3 & 4 & 5\end{array}$

\section{Reference List}

269. All citations provided in the text are contained in the reference list.

270. All citations provided in the reference list are contained in the text.

$\begin{array}{lllll}1 & 2 & 3 & 4 & 5\end{array}$

$\begin{array}{lllll}1 & 2 & 3 & 4 & 5\end{array}$

271. The names of all authors provided in the text are consistent with the $\begin{array}{lllllll}1 & 2 & 3 & 4 & 5\end{array}$ names presented in the reference list.

272. All authors are presented in strict adherence to APA guidelines.

$\begin{array}{lllll}1 & 2 & 3 & 4 & 5\end{array}$

273. All titles are written accurately and in strict adherence to APA $1120 \begin{array}{lllll} & 2 & 4 & 5\end{array}$ guidelines.

274. All publication dates in the reference list are consistent with those in the $\quad \begin{array}{lllll}1 & 2 & 3 & 4 & 5\end{array}$ text and are written in strict adherence to APA guidelines.

275. All sources are written accurately and in strict adherence to APA $1120 \begin{array}{lllll} & 2 & 4 & 5\end{array}$ guidelines.

276. Every aspect of the reference list strictly adheres to APA guidelines.

$\begin{array}{lllll}1 & 2 & 3 & 4 & 5\end{array}$

\section{$\underline{\text { Appendix }}$}




\section{Macrothink}

International Journal of Education

ISSN 1948-5476

2012, Vol. 4, No. 2

277. The appendix section contains samples of any researcher-made $1 \begin{array}{lllll}1 & 2 & 3 & 4 & 5\end{array}$ instruments.

278. All researcher-made instruments appear to be appropriate for the study. $\quad \begin{array}{llllll}1 & 2 & 3 & 4 & 5\end{array}$

279. The appendix section contains an appropriate number of informed $1 \begin{array}{llllll}1 & 2 & 3 & 4 & 5\end{array}$ consent forms.

280. Each informed consent form is written appropriately for the intended $\begin{array}{lllll}1 & 2 & 3 & 4 & 5\end{array}$ reader.

281. Each informed consent form contains all important information. $\quad \begin{array}{llllll}1 & 2 & 3 & 4 & 5\end{array}$

282. The information provided in each informed consent form is consistent $1 \begin{array}{llllll}1 & 2 & 3 & 4 & 5\end{array}$ with the information provided in the methods section.

\section{Number of Occurrences:}

Number of points assigned:

TOTAL SCORE FOR RESEARCH REPORT OUT OF 1410:

PERCENTAGE SCORE FOR RESEARCH REPORT:

RUBRIC EQUIVALENT SCORE OUT OF 60: 


\section{PART II: MIXED REPORTS SCORING CHECKLIST FOR QUALITY OF WRITING}

AND ADHERENCE TO APA STYLE

\section{MECHANICS}

\section{Name:}

Semester:

Date:

\section{DIRECTIONS:}

For each of the following statements, indicate the extent to which you agree or disagree, according to the scale below. (Note: Any statements which are not applicable will automatically receive a "strongly agree" rating.)

$1=$ strongly disagree $\quad 2=$ disagree $\quad 3=$ neutral $\quad 4=$ agree $\quad 5=$ strongly agree

\section{Title Page}

1. The title page contains all essential components.

$\begin{array}{lllll}1 & 2 & 3 & 4 & 5\end{array}$

2. The page header adheres strictly to APA guidelines.

$\begin{array}{lllll}1 & 2 & 3 & 4 & 5\end{array}$

3. The page header text is of high quality (e.g., grammar, punctuation).

$\begin{array}{lllll}1 & 2 & 3 & 4 & 5\end{array}$

4. The running head adheres strictly to APA guidelines.

$\begin{array}{lllll}1 & 2 & 3 & 4 & 5\end{array}$

5. The running head text is of high quality (e.g., grammar, punctuation).

$\begin{array}{lllll}1 & 2 & 3 & 4 & 5\end{array}$

6. The title adheres strictly to APA guidelines.

$\begin{array}{lllll}1 & 2 & 3 & 4 & 5\end{array}$

7. The title text is of high quality (e.g., grammar, punctuation).

$\begin{array}{lllll}1 & 2 & 3 & 4 & 5\end{array}$

\section{Introduction/Literature Review}

1. This section contains all the salient information.

2. No inappropriate information is presented in this section of the report $1123 \quad 3 \quad 4 \quad 5$ (including repetitive information).

3. This section is informative.

4. This section is entirely accurate.

$\begin{array}{lllll}1 & 2 & 3 & 4 & 5\end{array}$

5. This section does not contain any contradictions.

$\begin{array}{lllll}1 & 2 & 3 & 4 & 5\end{array}$

6. This section is comprehensive.

7. This section is written in strict adherence to APA guidelines (including $11 \quad 2 \quad 3 \quad 4 \quad 4 \quad 5$ margins).

8. This section is clearly written throughout.

$\begin{array}{lllll}1 & 2 & 3 & 4 & 5\end{array}$

9. The writing in this section is of high quality (e.g., grammar, punctuation).

$\begin{array}{lllll}1 & 2 & 3 & 4 & 5\end{array}$

\section{Method}

\section{Participants}

1. This section contains all the salient information.

$\begin{array}{lllll}1 & 2 & 3 & 4 & 5\end{array}$

2. No inappropriate information is presented in this section of the report $1123 \quad 3 \quad 4 \quad 5$ (including repetitive information). 


\section{MIMacrothink}

International Journal of Education

ISSN 1948-5476

2012, Vol. 4, No. 2

3. This section is informative.

$\begin{array}{lllll}1 & 2 & 3 & 4 & 5\end{array}$

4. This section is entirely accurate.

5. This section does not contain any contradictions.

$\begin{array}{lllll}1 & 2 & 3 & 4 & 5\end{array}$

6. This section is comprehensive.

$\begin{array}{lllll}1 & 2 & 3 & 4 & 5\end{array}$

7. This section is written in strict adherence to APA guidelines (including

$\begin{array}{lllll}1 & 2 & 3 & 4 & 5\end{array}$
margins).

8. This section is clearly written throughout.

$\begin{array}{lllll}1 & 2 & 3 & 4 & 5\end{array}$

9. The writing in this section is of high quality (e.g., grammar, punctuation).

$\begin{array}{lllll}1 & 2 & 3 & 4 & 5\end{array}$

\section{Instruments}

1. This section contains all the salient information.

$\begin{array}{lllll}1 & 2 & 3 & 4 & 5\end{array}$

2. No inappropriate information is presented in this section of the report $1123 \quad 3 \quad 4 \quad 5$ (including repetitive information).

3. This section is informative.

$\begin{array}{lllll}1 & 2 & 3 & 4 & 5\end{array}$

4. This section is entirely accurate.

$\begin{array}{lllll}1 & 2 & 3 & 4 & 5\end{array}$

5. This section does not contain any contradictions.

$\begin{array}{lllll}1 & 2 & 3 & 4 & 5\end{array}$

6. This section is comprehensive.

$\begin{array}{lllll}1 & 2 & 3 & 4 & 5\end{array}$

7. This section is written in strict adherence to APA guidelines (including $11 \quad 2 \quad 3 \quad 4 \quad 4 \quad 5$ margins).

8. This section is clearly written throughout.

$\begin{array}{lllll}1 & 2 & 3 & 4 & 5\end{array}$

9. The writing in this section is of high quality (e.g., grammar, punctuation). $\quad \begin{array}{lllll}1 & 2 & 3 & 4 & 5\end{array}$

\section{Procedure}

1. This section contains all the salient information.

$\begin{array}{lllll}1 & 2 & 3 & 4 & 5\end{array}$

2. No inappropriate information is presented in this section of the report $1 \begin{array}{llllll} & 2 & 3 & 4 & 5\end{array}$ (including repetitive information).

3. This section is informative.

$\begin{array}{lllll}1 & 2 & 3 & 4 & 5\end{array}$

4. This section is entirely accurate.

$\begin{array}{lllll}1 & 2 & 3 & 4 & 5\end{array}$

5. This section does not contain any contradictions.

$\begin{array}{lllll}1 & 2 & 3 & 4 & 5\end{array}$

6. This section is comprehensive.

$\begin{array}{lllll}1 & 2 & 3 & 4 & 5\end{array}$

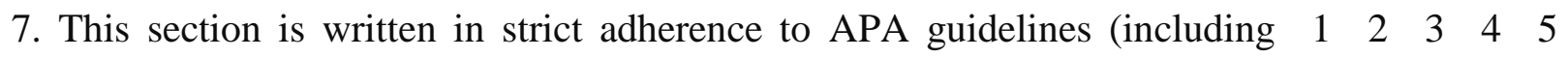
margins).

8. This section is clearly written throughout.

$\begin{array}{lllll}1 & 2 & 3 & 4 & 5\end{array}$

9. The writing in this section is of high quality(e.g., grammar, punctuation).

$\begin{array}{lllll}1 & 2 & 3 & 4 & 5\end{array}$

\section{$\underline{\text { Limitations }}$}

1. This section contains all the salient information. $\quad \begin{array}{lllll}2 & 3 & 4 & 5\end{array}$

2. No inappropriate information is presented in this section of the report $1 \begin{array}{lllll}1 & 2 & 3 & 4 & 5\end{array}$ (including repetitive information).

3. This section is informative.

$\begin{array}{lllll}1 & 2 & 3 & 4 & 5\end{array}$

4. This section is entirely accurate.

$\begin{array}{lllll}1 & 2 & 3 & 4 & 5\end{array}$

5. This section does not contain any contradictions.

$\begin{array}{lllll}1 & 2 & 3 & 4 & 5\end{array}$

6. This section is comprehensive.

$\begin{array}{lllll}1 & 2 & 3 & 4 & 5\end{array}$ 


\section{Macrothink}

International Journal of Education

ISSN 1948-5476

2012, Vol. 4, No. 2

7. This section is written in strict adherence to APA guidelines (including $1 \begin{array}{lllll}1 & 2 & 3 & 4 & 5\end{array}$ margins).

8. This section is clearly written throughout.

$\begin{array}{lllll}1 & 2 & 3 & 4 & 5\end{array}$

9. The writing in this section is of high quality (e.g., grammar, punctuation). $\quad \begin{array}{llllll}1 & 2 & 3 & 4 & 5\end{array}$

\section{$\underline{\text { Analysis }}$}

1. This section contains all the salient information.

2. No inappropriate information is presented in this section of the report $1122 \quad 3 \quad 4 \quad 5$ (including repetitive information).

3. This section is informative.

$\begin{array}{lllll}1 & 2 & 3 & 4 & 5\end{array}$

4. This section is entirely accurate.

5. This section does not contain any contradictions.

$\begin{array}{lllll}1 & 2 & 3 & 4 & 5\end{array}$

6. This section is comprehensive.

$\begin{array}{lllll}1 & 2 & 3 & 4 & 5\end{array}$

7. This section is written in strict adherence to APA guidelines (including $11 \quad 2 \quad 3 \quad 3 \quad 4 \quad 5$ margins).

8. This section is clearly written throughout.

$\begin{array}{lllll}1 & 2 & 3 & 4 & 5\end{array}$

9. The writing in this section is of high quality (e.g., grammar, punctuation).

$\begin{array}{lllll}1 & 2 & 3 & 4 & 5\end{array}$

\section{Number of Occurrences:}

\section{Number of points assigned:}

Total Score out of 305

\section{Percentage Score:}

\section{Rubric Equivalent Score out of 40:}




\section{Score Summary Sheet}

RUBRIC EQUIVALENT SCORE FOR CONTENT OUT OF 60:

RUBRIC EQUIVALENT SCORE FOR MECHANICS OUT OF 40:

\section{BONUS POINTS FOR INTRODUCTION/LITERATURE REVIEW}

( 1 = Material presented in this section is slightly more than was required)

$(2=$ Material presented in this section is more than was required $)$

( $3=$ Material presented in this section is substantially more than was required):

\section{BONUS POINTS FOR CONTENT IN PARTICIPANTS SECTION}

( $1=$ Material presented in this section is slightly more than was required)

( $2=$ Material presented in this section is more than was required)

( 3 = Material presented in this section is substantially more than was required):

\section{BONUS POINTS FOR CONTENT IN INSTRUMENTS SECTION}

( $1=$ Material presented in this section is slightly more than was required)

( $2=$ Material presented in this section is more than was required)

( $3=$ Material presented in this section is substantially more than was required):

\section{BONUS POINTS FOR CONTENT IN PROCEDURE SECTION}

( $1=$ Material presented in this section is slightly more than was required $)$

( $2=$ Material presented in this section is more than was required)

( 3 = Material presented in this section is substantially more than was required):

\section{BONUS POINTS FOR CONTENT IN LIMITATIONS SECTION}

( $1=$ Material presented in this section is slightly more than was required $)$

( $2=$ Material presented in this section is more than was required)

( 3 = Material presented in this section is substantially more than was required):

\section{BONUS POINTS FOR CONTENT IN ANALYSIS SECTION}

(1= Material presented in this section is slightly more than was required)

( $2=$ Material presented in this section is more than was required)

( 3 = Material presented in this section is substantially more than was required):

PENALTY POINTS FOR MECHANICS IN RESEARCH REPORT 
Number of missing, incomplete, or inconsistent references:

\section{TOTAL NUMBER OF POINTS:}

Comments: 
Appendix C

Instructor Feedback 
Most people believe that all schools are the same from the outside looking in (Raywid, 2001). The problem with that frame of mind is that schools are schools, not airplane factories or dairy farms; schools look like schools, and schools are run as schools, but with a little closer look, schools are extraordinarily different. The closer you get, the more different schools look. Each school has a distinctive feel.

This feel is so persistent and potent that we experience it immediately when we walk into a school. We are so accustomed to this experience that we worry about a school that lacks a particular feel. Somehow it has not been inhabited. It does not have a history, and it does not have a personality. We are not yet experiencing its culture.

Once we do feel a school's culture, however, it leaves a strong impression on $\underline{\mathbf{u s}}$. The combination of the structural design, the symbols, the artifacts, the look and behavior of the people, the conversations we had, and the treatment we received — all this and much morecreates a memorable impression.

One definition of school culture is the deep pattern of values, beliefs, and traditions that have been formed over the course of its history. A school culture is formed by its school community, which includes teachers, administrators, board members, business leaders, and the Comment [T05]: To whom does this Comment [T03]: Why is "we" underlined? Comment [T04]: According to APA (2010),
"For darity, restrict your "For darity, restrict your use of we to refer only to yourself and your coauthors (use lif you are
the sole author of the paper). Broader uses of we may leave your readers wondering to whom
you are refering; instead substitute an you are refering: instead, substitute an
appropriate noun or clanfy your usage" $(\mathrm{p}, 69)$ students themselves (Johnson \& Christensen, 2010). Every member of a school community is either part of the cultural mission of the school, an obstacle to that mission, or part of a subculture with a different mission (Daresh, 2007).

Our group believes that a positive school culture, from leadership on down, has a tremendous impact on the performance of Title I schools. In this research we hope to identify what parts of a positive culture impacts the schools the most, and how much leadership plays a part in developing that culture (Sergiovanni,_1984). A qualitative question includes attempting 
SCHOOL CULTURE

to understand the characteristics of a particular collection of people. For ideas to research, we Comment [T08]: Is this your opinion or do considered our own experiences as teachers (Johnson \& Christensen, 2010).

\section{Review of the Related Literature}

School culture includes the norms, values, and cultural artifacts shared by members of a

school, which affects the school's overall functioning (Engels, Hotton, Devos, Bouckenooghe, \& Aelterman, 2008). Lunenburg and Ornstein (2008) further explained culture to include the history of the organization,- myths and stories that explain the organization, cultural norms; heroes of the organization; $;$ and traditions, rituals and ceremonies of the organization. The information discovered about characteristics of effective schools, schools containing a positive culture, leadership in exemplary schools, and effects of positive school culture on student achievement will be shared you have a citation for this?

Effective schools and schools with a positive culture. effective schools involve strong leadership, a climate of expectation, an orderly atmosphere, and effective communication (Kelley, Thomton, \& Daugherty, 2005). Relationships, including student to student, teacher to student, teacher to family, administrator to staff, and school to community, are important in creating good school culture (Keiser \& Schulte, 2009). Healthy schools set high standards for academics, possess appropriate leadership, and collegiality (Macneil, Prater, \& Busch, 2009). Furthermore, according to Macneil et al. (2009), these effective schools contain Comment [T011]: Good! several factors, such as goal focus, communication, optimal power equalization, resource utilization, cohesiveness, morale, innovativeness, autonomy, adaptation, and problem solving adequacy. Teachers who feel good about their students, have confidence in their students' Comment [T012]: Good! abilities, and possess a trustworthy relationship between administration and staff are more 
qualities of healthy schools (Henderson et al., 2005). High commitment and performance also appear to be characteristics of schools that contain a healthy school culture (Engels Comment [T013]: This sentence does not make sense lam not sure what you are
attempting to say here, so I cannot editit. et al., 2008). Moreover, teacher collaboration is prevalent in a successful school (Johnson, Snyder, Anderson, \& Johnson, 1996). Supporting teachers and students, schools that possess shared views of fairness, justice, respect, cooperation, and compassion contain a positive sense of community) (Keiser \& Schulte, 2009). AAccording to Bryan and Henry (2009). Title I elementary schools must utilize the strengths found in children, their families, and communities. Comment [T014]: This sentence is both awkward and vague Comment [T015]: CITATION ERROR 2: This School-fanily-comm citation is not consistent with the reference list. School-family-community partnerships help in establishing strong environments that students need to be successful (Bryan \& Henry, 2009).

Leadership. the link of between effective school cultures and leadership Comment [TO16]: CITATION ERROR: This
citation is not consistent with the reference list Comment [T017]: Good

is supported by educational research findings (Macneil et al., 2009). In fact, there is a strong association $\underline{\text { between }}$ effective principals and school cultures that support learning (Engels et al., 2008). Southworth and Du Quesnay (2005) surmised that school leadership plays an important role in the growth of schools. Overall, school culture, and the relationships that shape it, is strongly guided by the principal (Macneil et al., 2009). A principal that who builds a culture promoting and encouraging learning helps students be successful. Viewing their school's environment in a holistic? way allows leaders better to shape the values, beliefs, and attitudes crucial to creating an ideal learning environment (Macneil et al., 2009). The principal should act as an entrepreneur, with a vision, who is able to inspire and motivate their staff (Engels et al., 2008). According to Howley, Woodrum, Burgess, and Rhodes (2009), a school operates best when leaders plan, implement policies, and initiate practices responsive to the culture of the community surrounding the school. School leadership is most effective when it embraces cultural norms and values of the community. In productive schools, 
SCHOOL CULTURE

answers to learning problems take place when administrators facilitate problem solving and express instructional standards (Johnson et al., 1996).

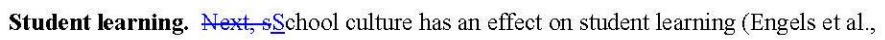
2008). In particular, Henderson et al. (2005) concluded that effective leadership increases student achievement. Teacher affiliation, resource support, and academic emphasis strongly correlated with student achievement as well. Schools that hold their students to high expectations and maintain orderly environments obtain higher student achievement on standardized tests (Henderson et al., 2005). In addition, a strong leader, the climate of the school, and the attitudes of faculty and staff can directly effectaffect student achievement (Kelley et al., 2009). According to Kelley et al. $(2005, p, 19)$,

sSchool climate may be one of the most important ingredients of a successful instructional program. Without a climate that creates a harmonious and well functioning school, a high degree of academic achievement is difficult, if not downright impossible to obtain..$\underline{(\mathrm{p} .19)}$

Conceptual/Theoretical Framework

The framework for this research proposal will be designed with the intentions of being Comment [T025]: Goodl

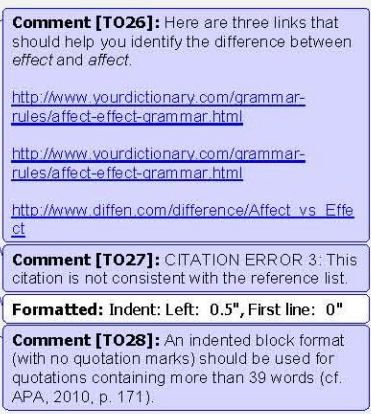
able to apply our conclusions to help in the future development of Title I schools. Lester (2005) states that "a research framework is a basic structure of the ideas (i.e., abstractions and relationship) that serve as the basis for a phenomenon that is being investigated." Theoretical framework is based on formal theory, whereas conceptual frameworks are based on a wide array of sources. With this in mind ${ }_{2}$ we have developed strong ideas that have built our framework. The first is that attitudes by staff and administration in schools have a strong influence in on children learning. Second, the implementation of Title I funding from the No

\section{cosn} Comment [T029]: Excellent! Comment [T030]: According to APA $(2010)$, and specific page citation or paragraph number for nonpaginated material (see section 6.05 ) in
the text ard include a complete reference in the the text and include a com
reference list" (p. 170). Comment [TO31]: While only should be used although whereas, and, or but in place of while atthough, whereas, and
(cf. APA, 2010, p. 84). 
Child Left Behind Act (NCLB) has had a positive influence on improving economically disadvantaged students education. Also, the Texas Assessment of Knowledge and Skills Comment [T032]: A citation is needed here. (TAKS) test scoring system is an adequate measurement of educational progress within Texas Public Schools. The details of this research structure are formulated from these impressions.

\section{Purpose of Study}

The purpose of this study will be to investigate the characteristics of the school culture in 10 exemplary--rated Title I campuses. The information is needed on school effectiveness with different populations, settings, and sites specifically, successful Title I campuses. Title I schools are very unique and encompass unique students with an abundance of different needs. Much more information is needed on how to help students and staff be successful at these types of schools. Although research has been conducted on characteristics of effective schools, feel there is a lack of research focusing on successful Title I schools specifically; and additional research is needed regarding these schools.

\section{We feel believe that this study will contribute to the knowledge base of what is known} about effective Title I schools. Furthermore, we believe the findings will help generate new ideas for other schools to implement. Finally, we hope the findings of this research will have an impact on the school at which we teach and other similar schools.

\section{Research Question(s) (Grand Tour Questions/Sub-Questions)}

The following research questions will be addressed: What are the strategies that are being taken by teachers, administration, and staff within exemplary schools to achieve and to maintain exemplary status? How has/does parental involvement impact the academic achievement of students in exemplary Title I schools? What are the distinguishing components 
in the climate and culture of exemplary Title I schools? What is the leadership style utilized to lead the campus to achieve exemplary status in Title I schools?

\section{Qualitative Hypothesis}

As Johnson and Onwuegbuzie (2004) indicate, within qualitative research it is difficult to test a hypothesis and make quantitative predictions. However, because of our prior experiences, we believe we can form strong predictions of what our research will produce. We believe that in exemplary Title I schools, we will be able to find similarities in overall organization, administration, and teacher attitudes, curriculum instruction as well as use of federal funds to execute school improvement plans. These schools will have similar internal structure to those that do not have Title I status. Teacher and administrative attitudes will be positive as they embrace the challenge of keeping their campus at an exemplary level, regardless of the student body being economically disadvantaged. The curriculum structure will still meet state requirements and should be strengthened with the implementation of additional Federal funding.

\section{Significance of the Study}

This research will target teachers, administrators, and other stakeholders in academic achievement. The researchers will identify the characteristics of exemplary Title I schools and the attitudes and behaviors of its students, teachers, and staff. It is hoped that fthe results of this study will identify effective concepts that are currently in place, and also enable the teachers, administrators and $_{2}$ and stakeholders to develop new programs, strategies, interventions, and so forth that will yield positive outcomes.

\section{Method}

Participants

Comment [T042]: Elementary, middle, and/or
secondary schools? Comment [TO43]: Excellert questions/। Comment [TO44]: This is OK. However, please note that hypotheses are rarely stated in
qualitative research because of the fear that it quaitative research because of the fear that it
will prevent the researcher from suspending judgment (epoche). Are you sure you want to state a qualitative hypothesis? 
The participants in this study will include administrators, teachers, and paraprofessionals of socioeconomically disadvantaged (Title I) campus that have achieved and/or maintained exemplary status. The sample members will be selected using convenience sampling. According to Onwuegbuzie and Collins (2007), a convenience sample consists of individuals who are available and willing to participate in a study. Purposeful random sampling and triangulation will be utilized to enable the collection of credible data from the selected respondents and to develop an understanding of the attitudes and behaviors that contribute to the different school's exemplary status. Johnson and Christensen (2010) mentioned triangulation involves looking for convergence of findings from various methods while studying the same phenomenon.

\section{Population context/size/population characteristics/selection-eligibility}

characteristics. The schools we will toek atstudy have to meet two major requirements. They must be considered Title I eligible and recognized as Exemplary each of the previous years. Title I schools are campuses that receive federal funding because of a high percentage of

low-income students. The Elementary and Secondary Education Act (ESEA) was enacted in 1965 by the Johnson Administration in an effort to give all children an equal environment to learn. "The purpose of this title is to ensure that all children have a fair, equal, and significant opportunity to obtain a high-quality education and reach, at a minimum, proficiency on

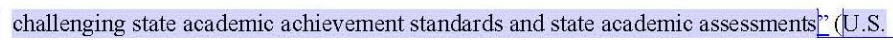
Department of Education, n.d.).2. This act is better known today as the $\mathrm{No}$ Child Left Behind Aet fNCLB . Forty percent of the students in eligible schools are considered low-income. Title I provides additional funds for after-school, intersession, and summer school programs. Funds are also allocated to help train parents, teachers, and school staff as well as hire additional teacher-s Comment [T049]: Elementary, middle, and/or secondary schools? Comment [T050]: Alternate sentence beginnings You have two consecutive sentences beginning with the words "The participants. As such, this part of you Formatted: Strikethrough

\begin{tabular}{|c|}
\hline iomment [T052]: Excellent! \\
\hline $\begin{array}{l}\text { Comment [TO53]: What is the approximate } \\
\text { population sze? }\end{array}$ \\
\hline \\
\hline $\begin{array}{l}\text { Comment [TO55]: Elementary, middle, and/or } \\
\text { secondary schools? }\end{array}$ \\
\hline Comment [TO56]: Good! \\
\hline $\begin{array}{l}\text { Comment [TO57]: Please note that APA (2010, } \\
\text { p. 112) stipulates that authors should use figures to } \\
\text { express "numbers that represent time, dates, ages, } \\
\text { sores and points on a scale, exact sums of money, } \\
\text { and numerals as numerals." }\end{array}$ \\
\hline $\begin{array}{l}\text { Comment [TO58]: Hyphenation should be used } \\
\text { when two or more words modify a noun (e.g, "son- } \\
\text { degree-secking programs" instead of "non degree } \\
\text { seeking program"; " "one-day orientation" instead of } \\
\text { "one day crientation"; cf. APA, 2010, p. 98) }\end{array}$ \\
\hline 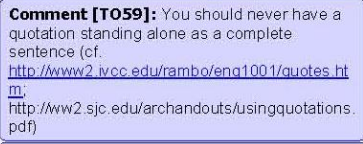 \\
\hline $\begin{array}{l}\text { Comment [TO60]: According to AFA (2010), } \\
\text { When quoting, allways provide the author, year, } \\
\text { and specific page citation or paragraph number } \\
\text { for nonpaginated material (see section } 6.05 \text { ) in } \\
\text { the text and include a complete reference in the } \\
\text { reference list" (p. } 170 \text { ) }\end{array}$ \\
\hline $\begin{array}{l}\text { Comment [TO61]: CITATIOH ERROR 4: This } \\
\text { is incorrectly presented Is this U.S. Department of } \\
\text { Education (n. da) or U.S. Department of Education } \\
\text { (n. .b)? If you cite authors with two works published } \\
\text { in the same year, then " } a \text { " and " } b \text { " must be included } \\
\text { to distinguish them. }\end{array}$ \\
\hline $\begin{array}{l}\text { ime atter you have first introduced it (cf. APA, } \\
2010,0.107 \text { ). }\end{array}$ \\
\hline
\end{tabular}


assistants and specialists. Additional equipment and materials also are purchased with the funds in an overall attempt to sclose the achievement gap "2 between low= and high--performance schools (U.S Department of Education, n.d.).

The second requirement is that the school has reached exemplary status all of the previous three 3 years ${ }_{2}$ as determined by the Texas Education Agency (TEA). There are three standards by which a campus may be labeled: Exemplary, Recognized, and Academically Acceptable. All three of these labels are determined by Texas Assessment of Knowledge and Skills (TAKS testsing scores. This test has five large areas that are measured: Reading, Writing, Social Studies, Mathematics, and Science. This test is giveninistered to students from third_-grade through 11 th grade. Testing for different subjects are staggered in years. For example, writing is tested in gGrades 4 and 7 , whereas social studies is graded in $\mathrm{g}$ Grades 8,10 , and 11 . To determine a school's standards, the number of students that score high enough to pass the test is divided by the total number of students. For a school to be Exemplary, at least $90 \%$ of students must pass all subject areas. For a school to be included in our research, they must officially meet these TEA requirements determine by TE(Fexas Edueation AgenoftEA 2010).

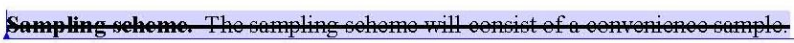$$
\text { ( }
$$

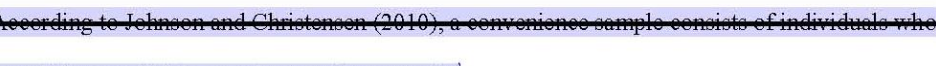

Sample size. Twenty five participants from each of the 10 exemplary Title I schools in the study will be interviewed. Johnson and Christensen (2010) mentioned that an intramethod mixing approach allows for quantitative as well as qualitative data to be obtained through a
Comment [T063]: Italics should be used
instead of double quotation marks to cite a letter, word, or sentence as a linguistic example (cf. APA, 2010, p. 91).

Formatted: Font Italic

Comment [T064]: Hyphenation should bo usd J modify a noun le o "nondegree-seeking nrosrams" instead of "non degree seeking programs", "one-day orientation" instead of "one day orientation"; cf. APA, 2010, p. 98) Comment [T065]: CITATTON ERROR 5: This is incorrectly presented. Is this U.S. Department of Education (n d.a) or U.S. Departnent of Education in the same vear then " $\mathrm{a}$ " and " $\mathrm{b}$ " must be included to distinguish them.

Comment [T066]: Please note that APA (2010 ingures to p. $x$ pes stpulates that authors should use ifgures to
express "numbers that tepresent time, dates, ages, scores and points on a scale, exact sums of money and numerals as numerals, Comment [T067]: Use the abbreviation each time after you have first introduced it (ct. APA 2010, p. 107).

Comment [T068]: According to APA (2010) "Consistent use of that for restictve clauses and which for nonrestricive clauses, which are set off with commas, will help make your writing

Comment [T069]: Use figures instead of words for numbers 10 and above (ct. APA Comment [T070]: Nouns followed by numerals or letters that denote a specific place in a number used instead of words to denote the numeral "Factor 1" instead of "factor one" (f. APA, 2010, 104).

Comment [T071]: While only should be used or but in place of whise (cf. APA, 2010, p. 84

Comment [T072]: Nouns foll lowed by numerals or letters that denote a specific place in a numbered Comment [T073]: Please be careful about

Comment [T074]: Excellent Comment [T075]: Use the abbreviation each time after you have first introduced it (ct. APA

Formatted: Double strikethrough

Comment [T076]: You have stated this

already.

Formatted: Double strikethrough

Comment [T077]: Good!

Comment [T078]: More information is neəded about your intramethod mixing. 
single method. The sample size for the intramethod questionnaire will depend on how many individuals respond.

Sample characteristics. It will be valuable to administer questionnaires to teachers, administrators, counselors, and any other teaching assistants who are involved in the day-to-day educational process on the campus. Johnson and Christensen (2010) explained that $\underline{\text { researchers }}$ are not limited to face-to-face interviews, because telephone interviews are acceptable forms of data collection.

\section{Instruments}

Twenty five faculty and staff at 10 exemplary Title I schools will be interviewed. The interview will consist of six open-ended questions. The interview questions are as follows:

1. In your own words, what role does culture play in your Title I school?

2. Describe the atmosphere at your school.

3. How are parents involved in their child's education?

4. How does the administration treat the faculty and staff?]

5. Which policies and procedures at your school help your students be successful?

6. What are the attitudes of faculty and staff at your school toward meeting an exemplary standard?

Probing question will include: Why do you feel that way? Can you think of some examples? Could you tell me more about your thinking on that? Each participant will be interviewed only once, using a formal interview guide approach. According to Johnson and Christensen (2010), this approach to interviewing involves specific questions being asked in any order; and the interviewer has freedom to rearrange the wording of questions. The interviews will be semi-structured, allowing the researchers to talk conversationally with the participants. 
Members of the research team will be responsible for interviewing at each school, using a neutral $L$ site within the school, as a setting. At each school, the research team will interview three administrators (the principal, one assistant principal, and one counselor), 15 classroom teachers, and seven paraprofessionals. The interviews will be scheduled during the interviewee's conference time and will last between 20 and 30 minutes. (Furthermore, a member checking or participant feedback approach will be implemented. This method consists of the researchers discussing conclusions made from the interviews with the actual participants to achieve accuracy (Johnson \& Christensen, 2010).

Rationale for selection of instrument. By interviewing participants, we will be able to obtain a better grasp of the school culture through the participant's own words. The interviews | will allows us to better better the participants' attitudes, thoughts, and beliefs about their school. In addition to the qualitative interviews, the research team will implement an Cominitiv. Comment [T086]: I am not sure what you mean by "neutral site:" intramethod questionnaire. Johnson and Christensen (2010) mentioned that an intramethod mixing approach allows for quantitative as well as qualitative data to be obtained through a single method. It is cost efficient and will provide data in various formats.

Purpose and content of instrument. The purpose of the questionnaire will be to obtain quantitative and qualitative data with a single tool. It will contain questions about the culture of the school, concerning topics such as leadership, relationships, parent involvement, curriculum, instruction, and community involvement. researchers.

Format of items. The questionnaire will consist of eight Likert-format items and 10 open-ended questions about school culture. The Likert-format items will hask participants to

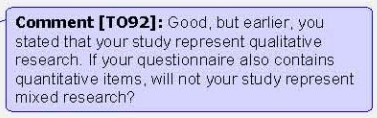
Comment [T087]: Do you plan to ask the principal and
question. "How does the administration treat the faculty and
staff?" Comment [T088]: Excellert!

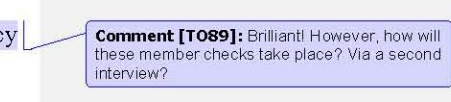
interview? Comment [T091]: Please be careful about your use of the possessive case research. If your que stionnaire also contains
quantitative items, will not your study represent quantitative items, wiln
mixed research?

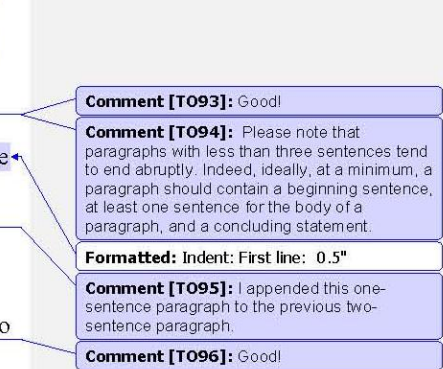




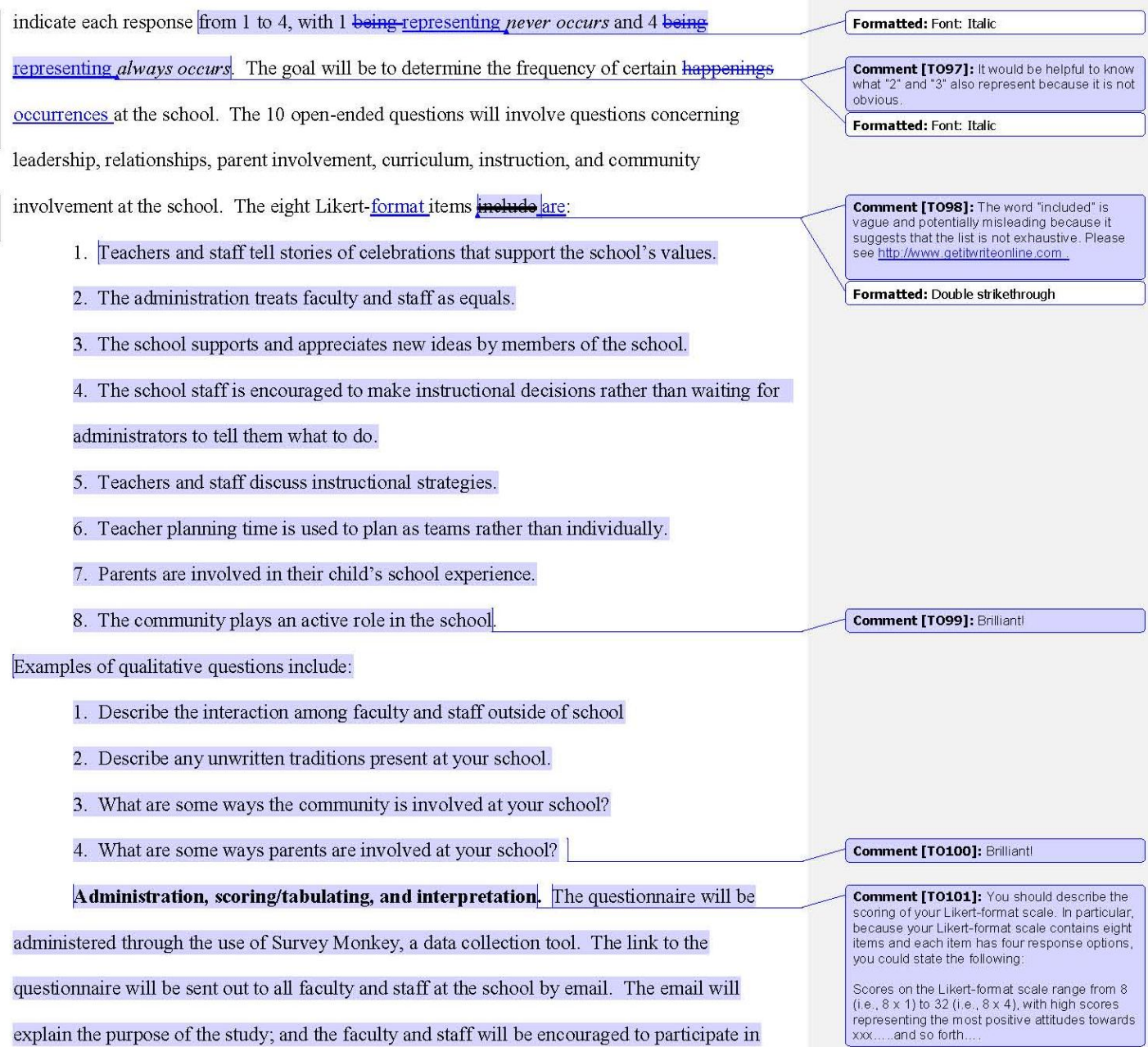


filling out the questionnaire. The responses for each of the Likert-format items will be tabulated. The open-ended responses will be tabulated as well.

Score reliability reported by instrument developers. Test-retest reliability will be obtained by administering the questionnaire to a test group of participants. One month later, the same questionnaire will be administered to the same group of participants; and the responses will be compared (Trochim, 2006).

Score reliability that will be computed in present study. The research team will conduct a follow-up study among the school, administering the same questionnaire several months later, to view the results obtained. The results of the questionnaire will be compared to those of the original study.

Content-related validity reported by instrument developers. A panel of experts on Comment [T0104]: OK, but I suggest that for
the eight LIKert-format items, you compute the eight LkKert-format items, you compute internal consistenc.
Cronbach's alpha).

school culture will review the questionnaire and suggest items that can be improved. The panel will let the research team know if the items will provide a good way of discovering Comment [T0105]: Avoid ending sentences or clauses with a preposition information about the culture of the schools.

Criterion-related validity reported by instrument developers. Results of the questionnaire will be compared with characteristics from the Correlates of Effective Schools Comment [T0106]: Good! Comment [T0107]: Please note that paragraphs with less than three sentences tend to end abruptly. Indeed, ideally, at a minimum, a paragraph should contain a beginning senterice. paragraph, and a concluding statement research by Lawrence Lezotte. These correlates consist of a safe and orderly environment, a Comment [T0108]: $A$ citation is needed here. climate of high expectations, instructional leadership, a clear and focused mission, the opportunity to learn and student time on task, frequent monitoring of student progress, and home-school relations (Lezotte, 1991). This comparison will help assure criterion-related validity by relating the data gathered in this study to another school effectiveness measure that has already been demonstrated to be valid. 
Construct-related validity reported by instrument developers. Multiple operationalism, which is the use of different measures of a construct, will be used (Johnson \& Christensen, 2010). The construct will be measured using a variety of ways, such as with interviews, quantitative questions, and qualitative questions. According to Johnson and Christensen (2010), the probability of acquiring a more complete as well as accurate representation of the construct increases as more measures of the same construct are implemented.

Development procedures for any new instrument. After discussing the data that we Wish-plan to collect, consulting previously conducted studies, and researching components of a school culture, the research team will develop the items on the questionnaire.

Validation procedures for any new instrument. Peer review, the sharing of thoughts and interpretations with one's peers, will be used. Participant feedback, where responses received are actually verified with the participants themselves, will be utilized as well (Johnson \& Christensen, 2010). The survey all also will be given to a test group of participants beforehand, to check for the understanding of the items included and the layout of the questionnaire.

Procedures

Ethical nature of data collection. All participants will be informed of the purpose, nature, and instruments used in the study through an informed consent form. This form will allow the participant to agree to be a part of a study after being informed of its purpose, procedures, risks, benefits, and confidentiality (Johnson \& Christensen, 2010). Additionally, the participants will be assured that all information shared or observed through the research will 
remain anonymous and confidential. This proposal will be submitted to the Institutional Review Board (IRB) for approval of this study as well.

Trainers of data collectors. Data collectors will be trained concerning what specific characteristics and qualities to look for while interviewing. Furthermore, they will be trained concerning probing question techniques and how to watch for non-verbal responses while interviewing participants.

Time-line for data collection. The intramethod questionnaire will be administered at the beginning of the study. The faculty will be given 1 week to respond to the survey at each school. After this, a reminder email will be sent out, encouraging those who have not completed the survey to do so. After 1 additional week, the survey will be closed. Concerning interviews, the research team will plan to conduct approximately five interviews a day at each school, over a time period of approximately 1 week.

Comment [T0113]: Good! Comment [T0114]: Please note that paragraphs with less than three sentences tend to end abruptly. Indeed, Ideally, at a minimum, a paragraph should contain a beginning sentenive,
at least one sentence for the body of a paragraph, and a concluding statement

Research paradigm. Our research paradigm will include pragmatism, because a mixed research approach will be carried out. Johnson and Christensen (2010) mentioned that a mixed research approach consists of both quantitative and qualitative components. Pragmatism involves the view of what works in practice and encourages social justice. According to

pragmatism, the research design that will best allow us to answer our research questions should be implemented (Johnson \& Christensen, 2010). Our qualitative-dominant research design w will Comment [T0118]: This sentence is both allow us to better gather the thoughts and happenings at 10 Title I exemplary schools.

Comment [T0116]: Athough l agree
you that you proposal represents mixed research, this is the first time you have specified that you plan to conduct a mixed methods research stud Comment [T0117]: Good!

Research design. The research design will consist of a qualitative-dominant concurrent method. This method includes the qualitative approach being given more weight than the quantitative, and each approach being conducted concurrently (Johnson \& Christensen, 2010). 
This mixed research design will help discover more about the school culture at the 10 Title I campuses, through the viewpoint of the faculty and staff who work there. Comment [T0120]: l love it

Verification procedures. The researchers will be certain to remain neutral while interviewing participants. Furthermore, results of similar studies will be researched and compared to the discoveries of this study.

\section{Limitations}

Threats to legitimation. First, according to Onwuegbuzie and Leech (2007), intemal credibility includes conclusions made within a setting or group, such as the truth value, applicability, consistency, neutrality, dependability, and/or credibility of explanations. Threats to internal credibility for our study include descriptive validity, reactivity, and researcher biased. Descriptive validity includes the researchers accurately documenting the each participant's words or views. This will be minimized by member checking, the process of systematically receiving feedback about conclusions made from the study group (Onwuegbuzie \& Leech, 2007). Furthermore, participants might be uncomfortable sharing truthful information with a researcher they do not know during the interview. This might be due to reactivity, changes that take place in participants when they know they are being observed (Johnson \& Christensen, 2010). During interviews, participants also might exhibit frontstage behavior. This consists of participants acting differently than the normal, displaying behaviors they want the researcher to see when they know they are being observed by the interviewer (Johnson \& Christensen, 2010). This threat will be minimized by the researchers clearly explaining the purpose of the study and reminding the participants that their responses will be completely confidential and anonymous. To continue, researcher biasedbias, involving personal assumptions of the researchers, might be evident to the participants and ultimately influence their attitudes,

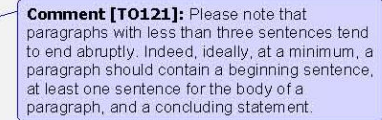

Comment [T0122]: Good! Comment [T0123]: Please be careful about your use of the possessive case. Comment [T0124]: I love it! Comment [T0125]: Excellent! Comment [T0126]: may $=$ permission, might $=$ possibility, can abilit

http://grammar.ccc.commnet.e du/grammar/a http://gramm

Uses of May and Might Two of the more troublescme modal auxiliaries are or seeking permission, might is the past tense of $m a$. Might is considerably more tentative than may. -May I leave class early? -If $I$ 've finished all $m y$ work and $I m$ really quiet, might T leave early
In the context of exp

In the context of expressing possib ility, moy and might are interchangeable present and future forms
and might + have + past participle is the past form: - She might be my adv isor next semester. - She may be my advi isor next semester. - She might have adv ised me not to take biology.
Ar oid confusing the sense of possib ility in $m$. with the implication of $m$ ight, that a hypothetical sitiation has not in fact occurred. For instance, let's say there's been a helicopter crash at the airport. In his initial report, before all the facts are gathered, a new scast After we discover that the pilot is in fact all rigit, the new scaster can now say that the pilot "might have been injured" because it is a hypothetical situation that has not occurred. Another example: a body had been identified atter much work by a detective. It body may have remained unidentified. "Since the body was, in fact, identified, might is clearly called for.

Comment [T0127]: Excellent! 
behaviors, or experiences (Onwuegbuzie \& Leech, 2007). Onwuegbuzie and Leech (2007) mention that research bias can be minimized by using unobtrusive measures, explaining the intentions of the researcher, carrying out interviews in a neutral place, and keeping a clear focus on the research questions.

On a different note, external credibility involves the ability to generalized findings of a study to various populations including different people, settings, and times (Onwuegbuzie \& Leech, 2007). Threats to external credibility include interpretative validity, researcher biased, reactivity, and order_-biased. Onwuegbuzie and Leech (2007) explained interpretative validity is Comment [TO129]: Good! the accuracy the that researchers have in correctly displaying the perspective of the participants and the meanings of their words and actions. This should be reduced by member checking, as explained before. Researcher biased, mentioned previously, is-also is an external threat, Comment [TO130]: Good! because the researchers' bias may hinder the data interpretation, making it ungeneralizable. (Peer Comment [T0131]: Ilove it1 debriefing, the process of obtaining an external view of the research process, will be carried out to decrease bias (Onwuegbuzie \& Leech, 2007). Reactivity, also mentioned previously, Comment [TO132]: Great ideal threatens the generalizability of the findings, because it will not be known if the same results will be obtained if this threat did not take place. Finally, order_biased, the order in which components are carried out, $\underline{\text { might } m a k e s ~ a ~ d i f f e r e n c e ~ i n t ~ t o ~ t h e ~ f i n d i n g s . ~ A l s o, ~ m o r e ~ v a r i a b l e s ~}$ might be related to school culture than what the questions asked cover. This threat will be minimized by triangulation, the process of implementing various methods and sources to obtain data (Onwuegbuzie \& Leech, 2007).

Analy sis

Method of analy sis. Concerning qualitative data collected, which will include interview responses and the open-ended responses gathered through the intramethod questionnaire, a

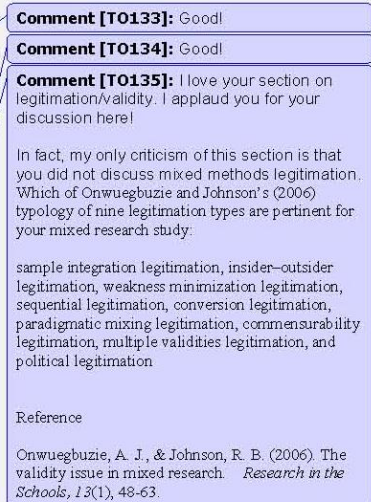


constant comparison analysis will be implemented. Leech and Onwuegbuzie (2008) stated that a constant comparison analysis will allow the researchers to create theories or a set of themes from data gathered. This approach will involve coding each qualitative response. The data will be broken down into segments and given a code that describes each segment. Next, the codes will be grouped into similar categories and themes will be formed (Leech \& Onwuegbuzie, 2008).

Regarding the quantitative data obtained through the eight Likert-format items on the questionnaire, the mean, median, mode, and range will be calculated on responses for each | These figures will be used to support the findings of the qualitative portion of the Comment [T0137]: The word "question" implies that the format always takes the form a question; yet, Likert-format scales, rating research. Furthermore, the numerical data collected will-also will be qualitized. This involves scales, and the like take the form of statements.
Thus, you should use the word "items" instead converting quantitative data into qualitative data (Johnson \& Christensen, 2010). The researchers Thus, you should "questions."
of

will described the findings of each question in words.

Comment [T0138]: | love it!

Each of the six researchers will be trained the exact same way in coding, and will participate in coding each of the interviews. Findings will be compared to assure intercoder reliability. This reliability involves consistency among various coders (Johnson \& Christensen, 2010). A posteriori codes will be implemented (codes based on experienthe data), and the data analysis will be exploratory in nature. This bottom-up or theory-generation approach will allow the researchers fully to compare their findings. Comment [T0140]: Excellent!

An exceptional proposal!! This is one of the best proposals that I have received to date of the Formatted: Left dozens of times I have taught this course over the last 17 years! In fact, your proposal, which was of high quality, was of a doctoral-level quality. I am very impressed and proud of you! 


\section{Macrothink}

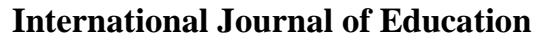

ISSN 1948-5476 2012, Vol. 4, No. 2

SCHOOL CULTURE

References

Bryan, J., \& Henry, L. (2008). Strengths-based partnerships: A school-family-community partnership approach to empowering students. Professional School Counseling, 12(2) 149-155. doi:10.5330/PSC.n.2010-12.149|

Daresh, J.C. (2007). Supervision Aas Pproactive Eleadership _- (4th ed.) Prospect Heights, IL: Waveland Press

Engels, N., Hotton, G., Devos, G., Bouckenooghe, D., \& Aelterman, A. (2008). Principals in schools with a positive school culture. Educational Studies, 34(3), 159-174. doi: $10.1080 / 03055690701811263$

Henderson, C. L., Buehler, A. E., Stein, W. L., Dalton, J. E., Robinson, T. R., \& Anfara, V. Comment [T0141]: Issue numbers should Cot be presented when the page numbers See for following website for a list of joumals and their pagination http://en.wikipedia.org/wiki/Joumal_pagination Formatted: Font: Not Italic ${ }_{t}$ Double

Comment [TO142]: CITATION ERROR 6 : Missing Dol number. Comment [TO143]: CITATION ERROR: This is not consistent with the text. Formatted: Default Paragraph Font, Font: (Default) Times New Roman

Formatted: Font: Not Italic

A. (2005). Organizational health and student achievement in Tennessee middle level schools. NASSP Bulletin, 89(644)), 54-73|doi:10.1177/019263650508964404 Howley, A., Woodrum, A., Burgess, L., \& Rhodes, M. (2009). Planning for culturally responsive leadership: Insights from a study of principals of exemplary schools. Educational Planning, $18(2)_{2}=12-24$ Comment [T0144]: Issue numbers should not Comment [TO145]: CITATION ERROR 7 : Formatted: Font: Not Italic

Formatted: Default Paragraph Font Formatted: Font: Not Italic

Johnson, R. B., \& Christensen, L. B. (2010). Educational research: Quantitative, qualitative, and mixed approaches (4th ed.). Thousand Oaks, CA: Sage.

Johnson, R. B., \& Onwuegbuzie, A. J. (2004). Mixed methods research: A research _ paradigm whose time has come. Educational Researcher, 33(7), 14-26 Formatted: Indent: Left: $0.5^{\prime \prime}$ doi: $10.3102 / 0013189 \times 033007014$

Johnson, W. L., Snyder, K. J., Anderson, R. H., \& Johnson, A. M. (1996). School work culture and productivity. The Joumal of Experimental Education, 64 $4_{\Sigma}=139-156$. doi: $10.1080 / 00220973.1996 .9943800$

Comment [TO146]: CITATION ERROR 8 :

Formatted: Defalt Paragraphont Font: Formatted: Defant Paragraph Font, Font: (Default) Times New Roman, $12 \mathrm{pt}$ 
Keiser, K. A., \& Schulte, L. E. (2009). Seeking the sense of community: A comparison of two elementary schools' ethical climates. The School Community Journal, 19(2) $=45-56$. Formatted: Font: Not Italic Kelley, R.C., Thornton, B., \& Daugherty, R. (2005). Relationships between measures of leadership and school climate. Education, 126(1), 17-23 Formatted: Font: Not Italic Leech, N. L., \& Onwuegbuzie, A. J. (2008). Qualitative data analysis: A compendium of techniques and a framework for selection for school psychology research and beyond. School Psychology Quarterly, 23, 587-604. doi:10.1037/1045-3830.23.4.587 Lester, F. (2005). On the theoretical, conceptual, and philosophical foundations for research in Comment [T0148]: CITATION ERROR 10: Formatted: Default Paragraph Font, Font: (Default) Times New Roman, $12 \mathrm{pt}$ mathematics education. $Z D M, 37,457-467$. doi:10.1007/BF02655854 Comment [T0149]: CITATION ERROR 11: Missing Dol number: Lezotte, L__ (1991). Correlates of Eeffective_sschools: The Ffirst and ssecond Formatted: Default Paragraph Font, Font: Ggeneration.

Effere Protuts, Lt4., Okemos, MI: Effective Schools Products. Ltd, 1991. Lunenburg, F._C., \& Ornstein, A.C. (2008). Educational administration: Concepts and practices. Belmont, CA: Wadsworth Centgage Learning.

Macneil, A._J., Prater, D. L., \& Busch, S. (2009). The effects of school culture and climate on student achievement. International Journal of Leadership in Education, 12(1), 73-84. Formatted: Font: Not Italic doi: $10.1080 / 13603120701576241$

Onwuegbuzie, A. J., \& Collins, K. M. T. (2007). A typology of mixed methods sampling designs in social science research. The Qualitative Report, 12(2), 281-316. Retrieved 8, 2011,from http://www nova.edu/ssss/QR/QR12-2/onwuegbuzie2.pdf Onwruegbuzie, A. J., \& Frels, R. K. (2011). The 13 step-research process. [PowerPoint Slides]. Retrieved from Sam Houston State University Online. 


\section{Macrothink}

Onwregbuzie, A. J., \& Leech, N. L. (2007). Validity and qualitative research: An oxymoron?

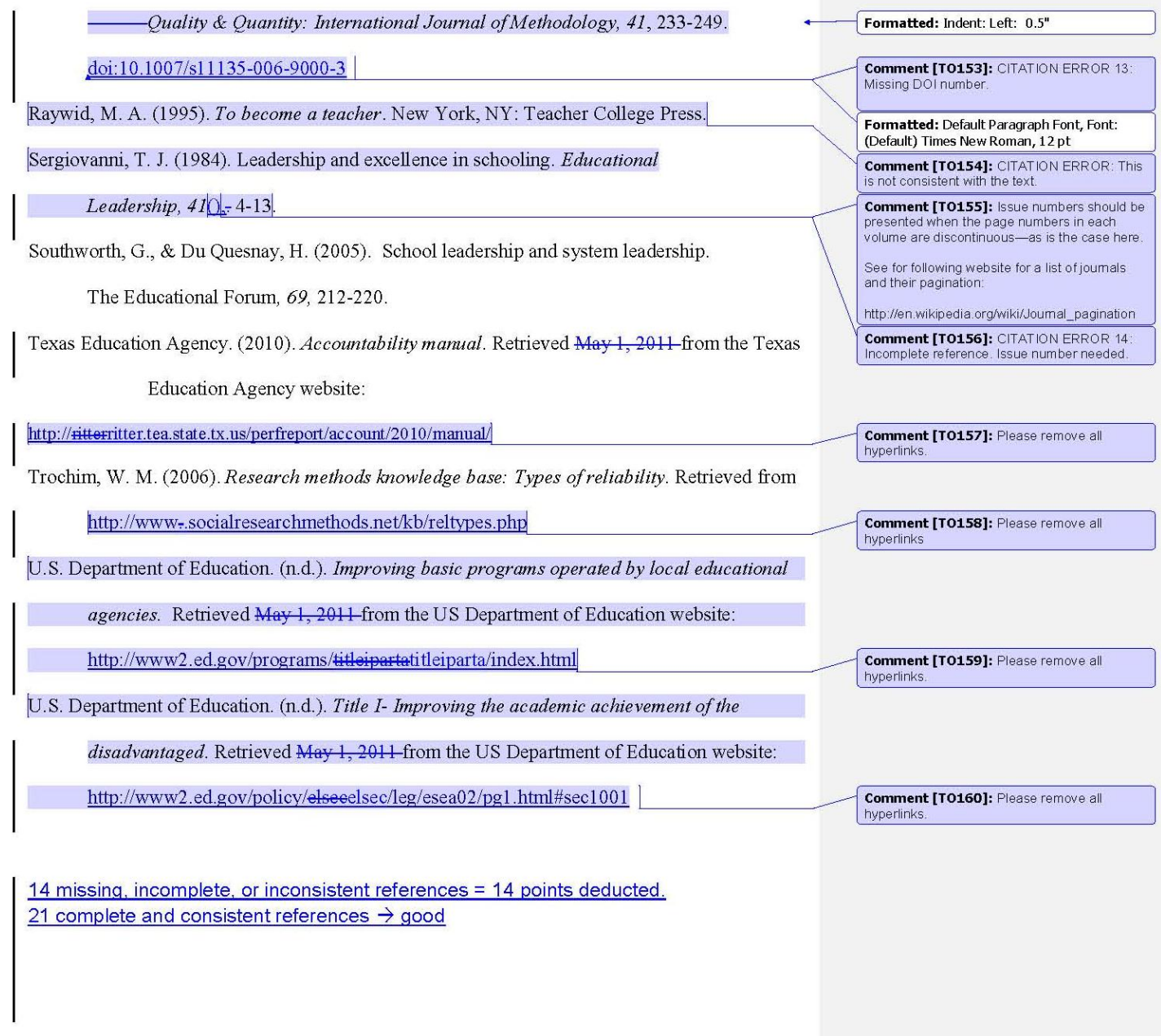

\section{Copyright Disclaimer}

Copyright reserved by the author(s).

This article is an open-access article distributed under the terms and conditions of the Creative Commons Attribution license (http://creativecommons.org/licenses/by/3.0/). 